\title{
Is Greed Contagious? Four Experimental Studies
}

\author{
Eric Cardella \\ Tamar Kugler \\ Eller College of \\ Rawls College of \\ Business \\ Management \\ Texas Tech University \\ University of Arizona \\ Jennifer S. Anderson \\ Goddard School of \\ Business and Economics \\ Weber State University \\ Terry Connolly \\ Eller College of Management \\ University of Arizona
}

$4 / 1 / 2019$

Corresponding author:

Eric Cardella

Energy Commerce and Business Economics

Rawls College of Business

Texas Tech University

Lubbock, TX 79409

Phone: 806-834-7482

Email: eric.cardella@ttu.edu

Keywords: Greed; Perception; Behavioral contagion; Common Pool Resource dilemma; Social dilemma; Laboratory experiments

We are thankful for financial support from the Center for Leadership Ethics at the University of Arizona and from the Rawls College of Business at Texas Tech University. 


\section{RUNNING HEAD: IS GREED CONTAGIOUS?}

This paper studies the behavioral consequences of greed perceptions in social interactions. Greed has attracted substantial attention in the business press (Haynes, Hitt \& Campbell, 2015), and in popular media (Ausick, 2010; Colvin, 2006; Dorfman, 2013; McGee, 2016; Pearlstein, 2016). Scholars have identified antecedents and consequences of greedy behavior; studies by Seuntjens, Zeelenberg, Breugelmans, and van de Ven (2015a), Seuntjens, Zeelenberg, van de Ven, and Breugelmans (2015b), Wang and Murnighan (2011), and Haynes et al. (2015) have explored the motivations of greedy actors, while Anderson (2014) and Gilliland and Anderson (2011) study greed perceptions and subsequent responses to greedy behavior. This paper aims to investigate contagion of greed in the context of social interactions.

Greed is seen (and often deplored) as a widespread human characteristic (Haynes et al., 2015; Sarna, 2010). It appears in many disciplines including behavioral economics (Wilke, 1991), political science (Collier, 2000), political economy (Collier \& Hoeffler, 1998), social psychology (Crossley, 2009; Grégroire, Lauffer \& Tripp, 2010), spiritual studies (Tickle, 2004), and culture (Robertson, 2001). However, despite recent work (Anderson, 2014; Gilliland \& Anderson, 2011; Haynes et al., 2015; Mussel \& Hewig, 2016; Seuntjens et al., 2015a, 2015b; Wang \& Murnighan, 2011), greed as a construct remains under-defined. Is greed distinct from selfishness, ambition, or self-interested behavior? Is an objective definition possible or is greed simply a negative evaluation of another's motivation? Does it relate to distributional inequality (Engel \& Zhurakhovska, 2016)? Perhaps the only agreement among scholars is offered by Seuntjens and colleagues: “Greed is an important motive” (2015b, p. 917).

Gilliland and Anderson (2011) note that "greed goes beyond ambition, self-interest, and even selfish behavior...”. It is associated with exploitative motives (Crossley, 2009; Lupia et al., 2000), moral violations (Robertson, 2001), and insatiable desire for more (Seuntjens et al., 2015b). We therefore define greed as a selfish motivation to acquire an unfairly excessive amount of a resource, at the expense of others. We focus on behavioral responses to perceptions of greed. We study the effects of perceptions for several reasons. First, from a methodological perspective it is difficult to identify greedy behavior and distinguish it from self-interested behavior, and it is often difficult to determine "when self-interest ends and when 


\section{RUNNING HEAD: IS GREED CONTAGIOUS?}

greed starts” (Wang \& Murnighan, 2011, p. 283). We, therefore, focus on perception and examine the behavioral reactions to perceived greed. Second, from a practical perspective, it should be perceptions of greed that drive behavioral response, rather than objective characterization. Thus, what is of primary interest is whether behavior responds in reaction to their own subjective (negative) perception of others' greed.

While previous research has explored the antecedents of greed perceptions, less is known about how people react after perceiving another as greedy (Sanfey et al., 2003). In our studies, we place participants in an environment that induces strong perceptions of greed, and examine how these perceptions shape future behavior. In particular, we address a possibility of greed contagion (Wang \& Murnighan, 2011). Writing in the aftermath of the 2008 financial crisis, Wang \& Murnighan speculated that greed contagion may have played a significant role: "The recent corporate scandals ... suggest that greed may be contagious, and capable of corrupting entire organizational and economic systems” (p. 307). Wargo, Baglini, and Nelson (2010) note the presence of corporate greed, especially in financial institutions, after the Great Recession. In short, the financial collapse may well have been an epidemic of greed. This suggests that greed perceptions may have important reactionary implications on behavior of impacted individuals.

In probing this suggestion, we distinguish between the actual behavior judged as greedy, and the evaluative process driving that judgment (Carnevale, Walker \& Walker, 2016). An individual may observe another engaging in a financial transaction, form a judgment that the behavior is greedy, and subsequently modify their own behavior. There are several paths by which the other's behavior can affect one's own. One might see another’s behavior as threatening a financial loss, and rearrange plans accordingly. In this case, one is reacting directly to the other's behavior. Alternatively, one's perception that another has behaved greedily might lead to anger, punishment, or withdrawal from interaction (Anderson, 2014), and those reactions will affect future behavior. In this latter case, behavior is driven by the evaluative assessment, causing greed perceptions to mediate the relationship between one's behavioral response and another's behavior, while in the former they are simply epiphenomenal: the perception are created as a result of another's behavior, but do not shape future behavior. Through a series of experiments, we systematically investigate if, and to what extent, there is greed contagion - do perceptions of greed result 


\section{RUNNING HEAD: IS GREED CONTAGIOUS?}

in individuals becoming greedier in subsequent interactions? We also explore the possible reputational effects of perceived greed.

While empirical research on greed perceptions is in its infancy, previous literature relating more broadly to behavioral motivations in social interactions provides an informative backdrop. There is substantial research, both empirical and theoretical, demonstrating the important role that emotions and beliefs have in shaping strategic behavior (Rabin, 1998; 2002; Elster, 1998; Loewenstein, 2000; Loewenstein \& Lerner, 2002). Bosman and van Winden (2002), Bosman et al. (2005), Dawes et al. (2007), Rueben and van Winden (2008), Crossley (2009), Kugler et al. (2012), and Colquitt et al. (2013) document evidence of negative emotions shaping behavior. Belief-based motivations such as reciprocity (Dufwenberg \& Kirchsteiger, 2004; Falk \& Fischbacher, 2006), guilt (Battigalli \& Dufwenberg, 2007) and anger/frustration (Battigalli et al., 2015) can also affect behavior. In light of these findings, we hypothesize that perceptions of greed, which are likely to invoke negative emotions, can shape future behavior.

We consider an incentivized common-pool resource (CPR) dilemma, which is the paradigm used in all our studies. Recall the definition of greed as a selfish motivation to acquire an unfairly excessive amount of a resource, at the expense of others. Over-extraction from a common-pool fulfills all aspects of this definition; high extractions are selfishly motived, perceived as unfair, and come at the expense of others.Tthe CPR dilemma features the structure and psychological framing to engender perceptions of greedy on the part of others and, hence, is a suitable platform for examining greed contagion.

Although reactions to greed perceptions offer one mechanism to explain a propensity to respond to greedy behavior in kind, other motives may shape behavior. Perhaps one reads an opponent's behavior as reflecting social norms (shared guidelines of expected and acceptable behavior, Birenbaum \& Sagarin, 1976). Bettenhausen and Murnighan $(1985 ; 1991)$ posit that norms are regular behavioral patterns that emerge through repeated interaction. Norms may thus motivate an individual's behavior in subsequent interactions (Cialdini, Reno \& Kallgren, 1990; Gino et al., 2009a; Gino, Gu \& Zhong, 2009b; Pillutla \& Chen, 1999). Alternatively, one may wish to punish an opponent's objectionable behavior, or retaliate for a loss (Bies \& Tripp, 1996; Boles, Croson \& Murnighan, 2000; Fehr \& Fischbacher, 2004a; Henrich et al., 


\section{RUNNING HEAD: IS GREED CONTAGIOUS?}

2006; Chaudhuri, 2011). One may also act in self-defense (Kramer, 2001), seeking restitution (Greenberg, 1993), or simply avoiding being taken twice for a sucker. Importantly, as part of our design we elicit

measures of perceived greed, which enable examining the extent to which these perceptions directly shape subsequent behavior above other motivations. Moreover, we gain some insights as to which motivations appear to be driving behavior.

Our paper is organized as follows. The next section describes the CPR dilemma. We then present four studies employing one or two rounds of a CPR dilemma. Study $1(N=159)$ examines how participants assess their opponents' greed in the first round, and how these greed perceptions shape second-round behavior when interacting with the same opponent. Study $2(N=296)$ addresses two questions: (a) whether Study 1 results replicate when participants interact with a new opponent in round 2 (true greed contagion), and (b) whether these new participants react to an opponent's greed reputation despite having no information about the opponent's past behavior. Study $3(N=82)$ isolates the possible effect of greed perceptions from the effects of having personally experienced the outcome of the behavior, by exposing participants to behavior of previous participants without incurring any of the consequences of this behavior, eliminating the possibility that participants are simply paying it forward. Study $4(N=176)$ examines changes in the focal participant's behavior in round two, after learning how greedy their own behavior in round one was perceived to be. The final section presents a synthesis of the findings, and proposes further study directions.

\section{The Common-Pool Resource (CPR) Dilemma and Greed Perceptions}

In this dilemma, individuals have access to a shared pool of resources, and make independent decisions about how much to withdraw. Remaining resources grow at a known, exogenous rate, to be withdrawn at a later point (see Gardner, Ostrom \& Walker, 1990 for a complete characterization). Withdrawing resources, while individually beneficial, prevents optimal growth of the resource and hurts the collective in the longterm, creating the dilemma (Ostrom et al.,2002; van Lange, Joireman, Parks \& Van Dijk, 2013; and Weber, Kopelman \& Messick, 2004; Samuelson, Messick, Rutte \& Wilke, 1984). Examples of real-world CPR dilemmas include fisheries, underground aquifers, and energy sources. In business contexts, Haynes, 


\section{RUNNING HEAD: IS GREED CONTAGIOUS?}

Campbell and Hitt (2017) describe an organizational-dilemma, documenting a negative relationship between CEO greed and shareholder wealth; more greedy CEOs take abnormally high compensation, thus reducing the firm's capital resources and hindering long-term returns.

Aside from the practical applications of CPR dilemmas, this paradigm is appropriate for investigating greed perceptions and their possible behavioral implications. Notably, one’s withdrawal imposes negative consequences on others, and on future resource availability, which ultimately leads to collective overharvesting (see Hardin, 1968, on the tragedy of the commons). Any individual's withdrawal comes at the expense of others. The total resource available for future consumption would be higher if all individuals withdrew less, letting the pool grow. Samuelson and colleagues (1984, p. 94) refer to this phenomenon as a social dilemma, where: “(a) each individual in a group receives a higher payoff for a socially defecting choice than for a cooperative choice, regardless of others' choices, and (b) each individual receives a higher payoff if all group members cooperate than if all defect.”

Gilliland and Anderson (2011) posit that individuals perceive others as greedy when they intentionally take more of a scarce resource than they need, and deprive others. The CPR dilemma provides individuals with precisely such an opportunity. The structure of a CPR dilemma creates incentives for taking more of the resource at the expense of others. We show in our studies that participants rated others who withdrew high amounts as greedy. They appeared to understand greed as an unfair and short-sighted pursuit of selfinterest without regard to others or the future. Our particular interest is in greed contagion: the possibility that greed perceptions can stimulate others to behave in kind in future interactions.

\section{Study 1: Perceived Greed and Contagion of Greedy Behavior}

Theory development and early empirics (van Lange et al, 2013) have identified three factors that lead participants to see opponent's behavior as greedy; (a) the amount one's opponent withdraws from the pool, (b) the extent to which one "loses out" (i.e., relative-deprivation), and (c) the extent to which one sees the opponent's behavior as motivated acquisitiveness (Anderson, 2014; Gilliland \& Anderson, 2011). An initial objective of Study 1 was to replicate the first two factors. We hypothesize a positive relationship between amounts withdrawn by another and perceptions of that other's greed (Hypothesis 1). Moreover, we expect 


\section{RUNNING HEAD: IS GREED CONTAGIOUS?}

this relationship to be moderated by one's own withdrawal such that when one withdraws more, they see others' withdrawals as less greedy (Hypothesis 2).

The central objective of Study 1 is to probe the proposition that exposure to an opponent's greedy behavior in an early interaction can stimulate a participant to behave more greedily (withdraw more) in a subsequent interaction. Behavioral contagion is well documented. Individuals cooperate in public-good games when others cooperate (Croson, Fatas \& Neugebauer, 2005; Fischbacher \& Gächter, 2010; Fischbacher, Gächter \& Fehr, 2001; Frey \& Meier, 2004; Gunnthorsdottir, Houser \& McCabe, 2007; Nikiforakis, 2010; Gächter, 2007), and defection typically leads to more defection (Fischbacher \& Gächter, 2010). People cooperate if their opponent had cooperated in the past (Ahn, Ostrom, Schmidt, Shupp \& Walker, 2001; Brandts \& Cooper, 2006a, 2006b; Knez \& Camerer, 2000; Schmidt, Shupp, Walker \& Ostrom, 2003). Trustworthy behavior promotes trust (Bohnet \& Huck, 2004; Bolton, Katok \& Ockenfels, 2004; Rigdon, McCabe \& Smith, 2007); people are more inclined to cheat after being exposed to cheaters (Gino, Ayal \& Ariely, 2009a); people are less generous following ungenerous behavior of others (Gray, Ward, \& Norton, 2014). We explore the possibility of a similar chain-reaction and hypothesize a positive relationship between an opponent's withdrawal in an initial round and one's own withdrawal in a subsequent round (Hypothesis 3).

However, greed contagion goes beyond reacting to behavioral outcomes; it links one's subsequent withdrawal to one's assessment of the greediness of an opponent's previous behavior. Thus, we postulate that greed perceptions mediate the relationship between an opponent's initial withdrawal and one's withdrawal in a subsequent interaction (Hypothesis 4).

\section{General Procedures}

The experiments were programmed in z-Tree (Fischbacher, 2007). All participants were randomly and anonymously matched, and engaged in a 2-person CPR dilemma. Participants were informed of an initial pool of stock from which they could withdraw immediately, or allow the stock to remain and grow for subsequent distribution at a higher rate. Examples of various combinations of withdrawals, and the resulting payouts were provided. Participants' decisions regarding the initial amount to withdraw were made 


\section{RUNNING HEAD: IS GREED CONTAGIOUS?}

independently and simultaneously. For clarification, from here we refer to matched participants as the participant or focal participant and the participant's opponent. No such adversarial language was used in the sessions. We used the following parameters in all studies:

- The common pool initially had 12 units of stock, and each of the two participants could withdraw any integer amount from 0 to 6 units. $^{1}$

- After individual withdrawals, any units remaining in the pool were multiplied by 1.5 and split evenly.

- The value of each unit of stock was US\$2. The total units each participant received was the sum of: (a) the units they initially took, and (b) $1 / 2$ of any remaining (multiplied) units in the pool.

- With the exception of Study 3, participants interacted in two distinct rounds of the dilemma (R1 and $\mathrm{R} 2$ ), and received cash payment for one of the rounds, selected at random.

\section{Study 1 Methods}

\section{Participants and design}

159 students from a large Southwestern U.S. university (56\% male; $\left.M_{\text {age }}=21.38\right)$ were recruited via email for a decision-making study. ${ }^{2}$ The sessions lasted approximately 45 minutes, and compensation was based on one randomly chosen round ( $M$ earnings $=$ US\$14.75).

\section{Procedure}

Participants were informed that they would participate in the CPR dilemma with another randomly selected person. After both participants made their first-round (R1) withdrawals, they were told how many stock units each had withdrawn, the total number of units remaining in the pool (before and after being multiplied by 1.5), the total units each had earned, and their total payoff.

\footnotetext{
${ }^{1}$ An artifact of this specific CPR dilemma is that there is no implicit scarcity of the resource in the pool; there are enough units of resource initially in the pool (12 units), and both participants can extract their full allowable amount (6 units each). This mitigates the possibility that the decision of how many units of stock to withdraw from the pool is being motivated by fear of there being insufficient resources.

${ }^{2}$ Of these 159 participants, 43 are from Study 4. Based on the experimental procedure in Study 4, described later, these participants are both operationally and strategically equivalent to the participants in Study 1; specifically, the 43 participants in Study 4 experience identical experimental procedure and instructions, and an identical software interface as those from Study 1. Therefore, we included this subsample of 43 participants from Study 3 in the analysis of Study 1 . We note that there are no significant differences between the two samples, and our results are generally robust if we include only the 116 participants initially recruited for Study 1, see supplementary online material.
} 


\section{RUNNING HEAD: IS GREED CONTAGIOUS?}

After R1, participants completed a questionnaire eliciting their perception of their opponent's greed. Perceived greed was measured using a 3-item scale (Anderson, 2014): (i) "How greedy was the other participant?” (ii) “Compared to the average person, how greedy would you say the other participant was?” and (iii) “How greedy do you think most other people would say the other participant was?” Participants rated each item from 1 (not at all greedy) to 7 (extremely greedy). The scale showed a good reliability with Cronbach's $\alpha=.93$. We use an average of these items as our greed perception measure. ${ }^{3}$

Participants were then informed they would be interacting in another (surprise) round of the same CPR dilemma (R2) with the same participant from R1. ${ }^{4}$ Importantly, participants made their R1 withdrawal decisions unaware that they would later: (a) evaluate their opponent's greed in R1, and (b) participate in a second round of the same dilemma, ensuring that R1 behavior and evaluation of their opponent's greed in R1 would not be affected by anticipation of R2. After making R2 withdrawal decisions, they again received feedback about their decisions, resulting outcomes, completed the greed perception questionnaire, and provided demographic information. Lastly, they were privately paid and dismissed.

\section{Results}

\section{Greed perceptions in $\mathrm{R} 1$}

We first examine the participant's perceptions of their opponent's greed in R1 (perceived opponent greed R1). Figure 1 shows the average of perceived opponent greed $R 1$ for each of 7 possible withdrawals in R1 (opponent withdrawal R1). The figure shows a strong positive correlation between perceived

\footnotetext{
${ }^{3}$ We also asked respondents to complete the 5-item scale developed by Grégoire et al. (2010) to provide an alternative measure of perceived greed (Cronbach's $\alpha=.90)$. Originally, Grégoire et al. developed this scale to measure perceived firm greed. We adapted the phrasing to fit the individual agent framing used in our experiment. The adapted 5-items are: (i) To what extent did the other person act selfishly?, (ii) To what extent did the other person intend to take advantage of you?, (iii) To what extent was the other person motivated by your interest?, (iv) To what extent did the other person try to abuse you?, (v) to what extent did the other person have bad intentions? These items were measured on a 5 item scale. Importantly, this scale strongly correlates $(r=.831$; p $<.001)$ with the 3-item Anderson (2014) scale. Moreover, our results are robust to using this alternative measure of perceived greed, although for brevity we do not report results using this alternative measure.

${ }^{4}$ Participants were not originally informed about R2, although, to avoid deception, they were told that the study had multiple parts. As with any experiment, information leakage across sessions is possible, so we cannot guarantee R2 was a surprise to every participant. However, the potential subject-pool is rather large (approximately 1000 students), other studies were being run at the lab over the several months we conducted our sessions, and participants were explicitly requested to not discuss the study; hence, we do not believe information leakage was a serious concern.
} 


\section{RUNNING HEAD: IS GREED CONTAGIOUS?}

opponent greed $R 1$ and opponent withdrawal $R 1$ ( $r=.77, p<.01)$, supporting the hypothesis that higher R1 withdrawals are associated with stronger perceptions of greed (H1).

\section{[Figure 1 here]}

Table 1 reports a regression of perceived opponent greed $R 1$ on (a) opponent withdrawal R1, (b) the participant's own withdrawal in R1 (own withdrawal R1), and (c) the interaction of the two. In all specifications, the coefficient of opponent withdrawal R1 is positive and significant. Model 2 shows no main effect of own withdrawal R1 on greed perceptions. However, in the full model (column 3) the coefficient of the interaction between opponent withdrawal $R 1$ and own withdrawal $R 1$ is negative and significant. The positive relationship between the amount withdrawn by a participant's opponent and the participant's perceptions of the opponent's greed is moderated by the participant's own withdrawal behavior. When a focal participant took more, that positive relationship was weaker, supporting the claim that when individuals withdraw higher amounts, they temper their evaluation of others' greed (H2).

\section{[Table 1]}

\section{Impact of perceived opponent greed in $\mathrm{R} 1$ on own choices in $\mathrm{R} 2$}

The second cluster of hypotheses focuses on how R2 behavior is affected by withdrawals in R1 and by participants' evaluation of their opponent's greed. Overall, results showed that participants, on average, withdrew significantly more in R2 (mean increase $M=.86$ units; $t(158)=-4.05, p<.01$ ). Our assertion that participants would withdraw more in R2 in response to higher R1 withdrawals by their opponent in R1 (H3) was supported; we found a positive relationship between the opponent's withdrawal R1 and the focal participant's own withdrawal $R 2(r=.42, p<.01)$. Additionally, the correlation between participants' perceived opponent greed $R 1$ and their own withdrawal $R 2$ was positive $(r=.38, p<.01$; Figure 2$)$. These results are consistent with the notion of greed contagion, and set the background for testing whether greed perceptions mediate the relationship between an opponent's R1 withdrawal and one’s own R2 withdrawal.

\section{[Figure 2]}

Before conducting mediation analysis, we regress the focal participant's own withdrawal R2 on (a) own withdrawal R1, (b) opponent withdrawal R1, (c) the interaction of the two, (d) the participant's assessment 


\section{RUNNING HEAD: IS GREED CONTAGIOUS?}

of perceived opponent greed R1, and (e) the participant's assessment of perceived opponent selfishness R1. The results are in Table 2. Columns 1-4 show positive coefficients of both own withdrawal $R 1$ and opponent withdrawal R1, and a negative interaction term coefficient. However, the analysis shows no effect of perceived opponent greed R1 on own withdrawal R2 (Columns 2 and 3), which suggests that perceptions of the opponent's greed in R1 do not affect focal participants' behavior in R2 above R1 behavior. Moreover, the coefficient on perceived opponent selfishness $R 1$ is not significant when it is included with perceived opponent greed R1 (Column 3) or without (Column 4).

\section{[Table 2]}

We conducted mediation analysis using Preacher and Hayes' (2004) PROCESS. We found no indication that greed perceptions mediate the relationship between an opponent withdrawal $R 1$ and one's own withdrawal R2; the bootstrapped 95\% confidence interval spanned zero ( $L L C I=-.046$ and $U L C I=.272)$. Because earlier findings demonstrated that one's own withdrawal R1 affected perceived opponent greed R1 (when interacted with opponent withdrawal R1), we also tested moderated mediation, using one’s own withdrawal R1 as a moderator. Results showed no indication of moderated mediation, the bootstrapped $95 \%$ confidence intervals spanned zero $(L L C I=-.025$ and $U L C I=.004)$. Although a participant's rating of their opponent's R1 greed was positively related with both the opponent's actual R1 withdrawal and their own R2 withdrawal, greed perceptions did not appear to mediate the two (H4).

\section{Spillover of R1 Outcomes on R2 Behavior}

Table 2 shows that R1 had strong effects on R2 behavior. While not our main aim, we perform some post-hoc analyses to examine alternative motivations connecting the two. We examine the difference between one's R1 withdrawal and the opponents R1 withdrawal affects R2. We plot the degree to which a participant's R1 withdrawal “compares” to their opponent's R1 withdrawal, against the participant's “adjustment” in the withdrawal between R1 and R2. Figure 3 displays R1 compare = (own withdrawal R1 - opponent withdrawal R1) on the x-axis (ranging from -6 to 6), and R2 adjust = (own withdrawal R2 own withdrawal R1) on the y-axis (same range). 


\section{RUNNING HEAD: IS GREED CONTAGIOUS?}

When the paired participants had the same R1 withdrawal ( $R 1$ compare $=0)$ there was almost no adjustment from R1 to R2; average adjustment is .65 units. Furthermore, of the 23 instance when $R 1$ compare $=$ 0, 17 (74\%) participants repeated their withdrawal in R2. In contrast, for pairs whose R1 withdrawals did not match ( $R 1$ compare differs from 0 ), there is a strong negative correlation between $R 1$ compare and $R 2$ adjust ( $r=-.71, p<.01)$, indicating that lower-withdrawing R1 participants (R1 compare $<0$ ) adjusted upward in R2. The mismatched R1 withdrawals converged in R2, but the adjustments were highly asymmetrical; relatively high-withdrawing R1 participants persisted in their withdrawls, while relatively low-withdrawing $\mathrm{R} 1$ participants increased their withdrawals. When $R 1$ compare $>0$, the relationship between $R 1$ compare and $R 2$ adjust is essentially flat ( $r=-.14, p=.23$ ), indicating no adjustment; when $R 1$ compare $<0$, the negative relationship between $R 1$ compare and $R 2$ adjust is negative $(\mathrm{r}=-.66, \mathrm{p}<.01)$. This asymmetric pattern is exemplified at the extremes: when $R 1$ compare $=-6,76 \%$ (13/17) increased their R2 withdrawal from 0 to 6 units, while when $R 1$ compare $=6$, $75 \%(12 / 16)$ persisted in withdrawing 6 units in R2.

\section{[Figure 3]}

\section{Discussion}

Study 1 casts doubt on the simplest model of greed contagion, where participants who perceive their opponent as greedy in an initial interaction react to this perception by becoming greedier in subsequent interactions against the same opponent. While we found that high R1 opponent withdrawals were perceived as greedy, the opponent's R1 behavior was a better predictor of the focal participant's R2 behavior than was their assessment of their opponent's greed. Greed perceptions were associated with high R1 opponent withdrawals, but did not mediate participants’ increased R2 withdrawals. Perceptions did not affect R2 above behavior in R1. Rather, we observed that behavior in R1 shaped behavior in R2 in a manner consistent with a “compare and adjust” process. Participants withdrawing larger amounts enjoy a profitable R1 and do not reduce their subsequent withdrawal. Individual withdrawing low amounts, however, had an unprofitable R1 and were in essence victims of their opponent's greedy behavior. This negative outcome 


\section{RUNNING HEAD: IS GREED CONTAGIOUS?}

results in a stronger behavioral response (Baumeister, Bratslavsky, Finkenauer, \& Vohs, 2001; Keysar, Converse, Wang, \& Epley, 2008; Gray et al., 2014).

This comparison and adjustment pattern may be driven by several motivations. Perhaps participants’ increased withdrawals are a self-interested defense against losses in R2, an attempt to avoid being taken twice for a sucker, or intended as reciprocal punishment. Perhaps their opponent's R1 behavior suggests a norm for acceptable behavior. The stability of matched R1 withdrawals suggests that equity may be involved. Study 2 attempts to narrow this range of alternative accounts, exploring (a) the effect of interaction with new opponents in R2, and (b) the effect of knowing only the opponent's reputation for greed, not their actual behavior.

\section{Study 2: Interaction with New Opponents and Effects of Greed Reputation}

Study 1 revealed that opponent behavior in R1 predicted participants' R2 behavior better than perceptions of their opponent's greed. The design of Study 1 allows reciprocity or punishment motivations to "crowd-out” the potential effect of greed contagion. The first goal of Study 2 is to more cleanly test greed contagion by effectively shutting down the reciprocity channel. We retain the general structure of Study 1 , but have participants interact with different opponents in R2.

Previous studies have documented behavioral spillovers in social interactions. Schmidt et al. (2001) found that previous outcomes in a prisoners' dilemma influence behavior in future interactions with new partners. Cason, Savikhin, and Shermeta (2012) demonstrated that previous experience with coordination facilitates coordination with new partners. Gray et al. (2014) find spillover in dictator games: people who receive unfair allocations pay it forward by giving less to a different person. Conformity to social norms spills over to future interactions with new members (Bettenhausen \& Murnighan, 1991; Pillutla \& Chen, 1999). Our interest is whether an opponent's R1 behavior spills into the focal participant's behavior against a new opponent in R2, and whether this R2 behavior is mediated by the participant's perceptions of their R1 opponent's greed. To this end, Study 2 participants were divided into two groups, incumbents and new participants. Incumbents completed R1 and then evaluated their opponent's greed as in Study 1. In R2, 


\section{RUNNING HEAD: IS GREED CONTAGIOUS?}

incumbents were matched with new participants who did not participate in R1. However, new participants received information about how greedy their opponent was in the past.

Two important implications follow. First, because the incumbent participants play R2 against a new opponent, there is little scope for reciprocity motivations to affect their R2 behavior. Therefore, if the incumbent's R2 behavior toward a new opponent is directly affected by their perceptions of their R1 opponent's greed, this would present a strong case for greed contagion. Second, the new participants, who only partake in R2, are only given information about the previous (perceived) opponent greediness; ${ }^{5}$ hence, they are receiving a context-free evaluation of their opponent's perceived greed. In this sense, we can separate the possible reputation effects of perceived greed from retaliation or reciprocation.

We first propose a relationship between an opponent's R1 withdrawal and a participant's R2 withdrawal when paired with a new partner in R2. Specifically, we expect a positive relationship between withdrawals of an incumbent's opponent in R1 and the incumbent's own withdrawal in R2 when paired with a new opponent (Hypothesis 5). We further hypothesize that the potential mechanism that accounts for this relationship is greed perceptions: the positive relationship between an incumbent opponent's R1 withdrawal and an incumbent's R2 withdrawal is mediated by greed perceptions (Hypothesis 6). This would indicate true greed contagion, as the incumbent participant's R2 behavior would be driven by perceptions of their R1 opponent's greed.

Study 1 showed that R2 withdrawals were influenced by knowing the opponent's R1 withdrawal, but not by perceptions of the R1 opponent's greed. The second goal of Study 2 was to examine what happens if participants do not directly observe their opponent's behavior, but are only informed about the opponent's greed reputation. Substantial research indicates the importance of one's reputation in shaping the behavior of others. People are more cooperative when interacting with others who have a cooperative reputation in helping activities (Bolton, Katok \& Ockenfels, 2005; Seinen \& Schram, 2006), public goods games (Brandt, Hauert \& Sigmund, 2003; Milinski, Semmann \& Krambeck, 2002), and prisoners’ dilemma games (Duffy

\footnotetext{
${ }^{5}$ Specifically, these new participants are informed that this information about their opponent is based on a reported perception of their opponent's opponent in a previous interaction.
} 


\section{RUNNING HEAD: IS GREED CONTAGIOUS?}

\& Felovich; 2002). Participants show more trust in others who have a trustworthy reputation (Bohnet \& Huck, 2004; Bolton et al., 2004; Charness, Du \& Yang, 2011; Dulleck, Kerschbamer \& Sutter, 2011), and are more generous in dictator games toward others who had a more generous reputation (Servátka, 2009). Research in organizational justice suggests that participants are more likely to retaliate against individuals who have a reputation for being unfair (Brebels, De Cremer \& Sedikdes, 2008; Jones \& Skarlicki, 2005; Skarlicki \& Folger, 1997; Colquitt et al., 2013).

We designed Study 2 to test the effects of a greedy reputation. We propose a positive relationship between a new participant's R2 withdrawal and their opponent's greedy reputation from R1 (Hypothesis 7). In R2, new participants were not informed of their opponent's behavior in R1, but only of their incumbent opponent's greed reputation, as rated by the incumbent's original opponent in R1.

Finally, Study 2 explores whether incumbents try to manage their reputation. Reputation is important to collective action and fostering cooperation (Fehr, 2004a), as well as efficient functioning of markets, especially online (Bolton et al., 2013). Research indicates that individuals work to establish a positive reputation (Brandt et al., 2003; Engelmann \& Fischbacher, 2009; Milinski et al., 2002; Panchanathan \& Boyd, 2004; Bolton et al., 2013). Milinski et al. (2002) found that people aim to garner a cooperative reputation when playing a public-goods game repeatedly, while Engelmann and Fischbacher (2009) found that people strategically garner a cooperative reputation in repeated helping games. Even children deliberately manage their reputation (Aloise-Young, 1993; Engelmann, Herrmann \& Tomasello, 2012; Piazza, Bering \& Ingram, 2011). These findings inform our hypothesis that incumbents who are warned that their R1 greed reputation would be shared with a new opponent in R2 would manage their reputation by withdrawing less in R1 compared to incumbents who were not warned (Hypothesis 8).

\section{Study 2 Methods}

\section{Participants and design}

296 students from a large Southwestern US University (57\% male; $\left.M_{\mathrm{age}}=20.65\right)$ participated in this study. None participated in Study 1. Sessions lasted approximately 45 minutes ( $M_{\text {earnings }}=$ US\$14.75).

\section{Procedure}




\section{RUNNING HEAD: IS GREED CONTAGIOUS?}

We randomly assigned participants into two groups: incumbents and new participants. Upon arrival, incumbents were seated in the laboratory and new participants were taken to a separate room. Incumbents learned that they would participate in two rounds of the CPR dilemma against two different opponents. Specific procedures were similar to Study 1 up to the greed perception questionnaire after R1. Incumbent participants were randomly assigned to two conditions. In the warned condition, incumbent participants were told that their R1 opponent would evaluate how greedy they were in R1, and that their new R2 opponent would receive this greed rating (their reputation) before R2. In the unwarned condition, incumbent participants were not informed that their greed reputation would be revealed to their new R2 opponent. This allowed testing whether people manage their reputation by comparing the R1 withdrawals of incumbents that were warned to incumbents not warned.

While the incumbents completed R1, new participants were informed that they would be matched with an incumbent who had previously participated in a 2-person task. No details regarding the task were provided. However, they were informed that they would receive information about how greedy their paired incumbent was in this previous task. ${ }^{6}$ Once the new participants entered the laboratory, the rest of the procedure was identical to Study 1.

\section{Results}

\section{Incumbent Behavior}

As in Study 1, withdrawals were significantly higher in R2 than in R1. The mean increase across all incumbents was $M=1.22$ units $\left(t(147)=6.61, p<.01\right.$; for comparison, Study $1 M_{\text {increase }}=.86$ units; $t(158)$ $=-4.05, p<.01$ ). Table 3 reports several regressions of the focal incumbent's own withdrawal $R 2$ on: (a) opponent withdrawal R1; (b) the focal incumbent's own withdrawal R1; (c) the interaction of these two, (d)

\footnotetext{
${ }^{6}$ The new participants were told the following: "Before you choose how many units of stock to take from the common account, you will receive information about how greedy the person you are paired with was while participating in a previous task. In particular, the person you will be paired with has previously completed another 2person task over in the other room. At the completion of that task, we asked that person's partner to evaluate how greedy they had been on a scale from 1 to 7 in the task; where 1 is "not at all greedy" and 7 is "very greedy". Before making your stock withdrawal decision in the above described task, we are going to tell you this level of greed of the person you are paired with.” Before making their withdrawal decision, new participants had the greed score of their opponent displayed on their screen.
} 


\section{RUNNING HEAD: IS GREED CONTAGIOUS?}

the focal incumbent's perceived opponent greed R1, and (e) the focal incumbent's perceived opponent selfishness R1. In the first model, the coefficients of both own withdrawal R1 and opponent withdrawal R1 were positive and significant, replicating Study 1, and supporting H3. The interaction term was negative and significant, also replicating Study 1 . While the correlation between the withdrawal of the incumbent's opponent in R1 and the incumbent's own R2 withdrawal was modest $(r=.21, p<.01)$, it is perhaps larger than expectation given that opponents in R1 and R2 were different people. This suggests behavioral contagion: changes in an incumbent's behavior toward a new opponent were correlated with their original opponent's behavior. When an incumbent's original R1 opponent withdrew more from the pool, the focal incumbent, in turn, withdrew more in R2 against a new opponent.

\section{[Table 3]}

Models 3 and 4 show that the coefficient of perceived opponent greed R1 was not significant, and the addition of greed perceptions or selfishness perceptions to the model did not increase the predictive power of an incumbent's R2 withdrawal. Mediation analysis revealed that greed perceptions failed to mediate the relationship between the withdrawal of the incumbent's opponent in R1 and the incumbent's own withdrawal in R2, in contrast to H6. The bootstrapped 95\% confidence interval spanned zero (LLCI = - .193 and $U L C I=.208)$.

\section{[Figure 4]}

\section{Spillover of R1 Outcomes to R2 Behavior}

As in Study 1, R1 behavior played a role in shaping R2 behavior. We, again, provide a post-hoc examination of the behavioral spillovers from R1 to R2 by examining how R2 behavior adjusts in response to differences in R1 behavior between the paired participants. Figure 4 reveals that the compare-and-adjust process better characterizes incumbent R2 behavior. The Figure displays R1 compare = (own withdrawal $R 1$ - opponent withdrawal R1) on the $\mathrm{x}$-axis, and $\mathrm{R} 2$ adjust = (own withdrawal $\mathrm{R} 2$ - own withdrawal R1) on the y-axis. When the paired participants had similar R1 withdrawal ( $R 1$ compare $=0)$ there was almost no adjustment in withdrawal from R1 to R2; the average adjustment is 1.17 units. Of the 24 instances when 


\section{RUNNING HEAD: IS GREED CONTAGIOUS?}

$R 1$ compare $=0,67 \%(16)$ participants repeated the R1's withdrawal in $\mathrm{R} 2(R 2$ adjust $=0)$. These results replicate Study 1.

Conversely, for pairs whose R1 withdrawals did not match ( $R 1$ compare $\neq 0)$ the adjustment in withdrawal from R1 to R2 shows the same asymmetrical pattern from Study 1 . There is a strong negative correlation between $R 1$ compare and $R 2$ adjust $(r=-.58, p<.01)$, indicating that lower-withdrawing R1 participants adjusted upward in R2. High-withdrawing R1 participants persisted in withdrawing high amounts in R2, while low-withdrawing R1 participants moved closer to their opponents by increasing their $\mathrm{R} 2$ withdrawals. When $R 1$ compare $>0$, the relationship between $R 1$ compare and $R 2$ adjust is not significant $(r=-.04, p=.77)$, indicating no adjustment. However, when $R 1$ compare $<0$ the negative relationship between $R 1$ compare and $R 2$ adjust is strong and significant ( $r=-.50, p<.01)$, indicating larger adjustments.

\section{New Participant Behavior}

We examined the relationship between the new participants' withdrawal in R2 and the greed reputation of their paired incumbent opponents'. Figure 5 displays new participants' average own withdrawal R2 for each of the possible greed reputation scores of their incumbent opponent, and shows no relationship between new participants' mean own withdrawal $R 2$ and their opponent's greed reputation; $(r=.12, p=$ .15). Interestingly, the unused information is meaningful; greed reputation correlated strongly with the incumbent opponent's R1 withdrawal $(r=.78, p<.01)$, and moderately with the incumbent opponent's withdrawal in R2 $(r=.30, p<.01)$. Nevertheless, reputation information was essentially ignored by new participants as their R2 withdrawals were unaffected by the greed reputation of their opponent, failing to support Hypothesis 7.

\section{[Figure 5]}

\section{Managing a Greedy Reputation}

We also proposed that incumbents who were warned that their greed reputation from R1 would be reported to their new R2 opponents would reduce their R1 withdrawal to manage this reputation (H8). To test this, we compared mean incumbent R1 withdrawals in the warned and unwarned conditions (Figure 6). 


\section{RUNNING HEAD: IS GREED CONTAGIOUS?}

The mean own withdrawal R1 of incumbents in the warned condition was lower than in the unwarned condition, but this difference was not statistically significant $(M=2.75$ and 3.43 respectively; $t(146)=1.89$, $p=.06)$. Thus, the data provides little evidence that incumbent participants sizably changed their behavior to decrease their greedy reputation, failing to support Hypothesis 8. Taken together, findings from Study 2 indicate that the behavior of both incumbent and new participants was largely unaffected by information related to greed perceptions.

\section{[Figure 6]}

\section{Discussion}

In Study 2, we attempted to instantiate greed contagion using a different procedure than Study 1; incumbents participated in two repetitions of the CPR dilemma, with two different opponents. This design allowed for a cleaner test of greed contagion, as matching incumbents with a new opponent eliminated motives such as direct punishment or reciprocity toward one's original opponent. We found that while focal participants' own R2 withdrawals against a new opponent were correlated with their original opponent's R1 withdrawals and with their own R1 withdrawals, this relationship was not mediated by greed perceptions. We found little evidence of greed contagion despite robust perceptions of greed associated with high withdrawals. Further supporting the idea that greed perceptions are epiphenomenal in these types of interactions, we found no evidence that learning an opponent's greed reputation affected a new participant's withdrawal, and no real evidence that incumbents tried to manage said reputation.

Instead, the observed spillover for incumbents from R1 to R2 is better characterized by an asymmetric compare-and-adjust process. Adjusting behavior against new opponents in R2 renders certain motives, such as punishment, unlikely. Rather, this spillover would support a mechanism akin to paying-it-forward (Gray et al., 2014). This suggests that a plausible mechanism is norm learning in R1, that then impacts R2 behavior, despite this being an interaction with a new opponent.

\section{Study 3: Exposure to Past Greed}

In Study 2, incumbents participated in two repetitions of the CPR dilemma against two different opponents. We found, as in Study 1, that incumbents' R2 withdrawals were not directly affected by their 


\section{RUNNING HEAD: IS GREED CONTAGIOUS?}

perception of their opponent's greed in R1. While this design eliminates the possibly that R2 behavior is driven by reciprocity or punishment, there still is a possibility that incumbent behavior in R2 is affected by the experience of greedy behavior in R1: the incumbent's evaluation of how greedy their opponent was in $\mathrm{R} 1$ is formed via their interaction with the opponent and their personal experience of the associated opponent greed. Hence, the effect of this greed perception is inherently coupled with the experience that the incumbent had in R1. This is potentially problematic in light of the paying it forward findings from Gray et al. (2014) where peoples’ personal experience of the implications of greedy behavior results in them offering lower amount when they act as dictators.

In study 3, we further isolate the possible behavioral effect of greed perceptions by shutting down this channel of having personally experienced the outcome of R1. In this study, participants merely observe the behavior of a participant from a previous CPR dilemma (in which they did not take part), evaluate how greedy that person was, and then participate in an unrelated CPR dilemma themselves. This design allows testing how greed perceptions - without personal experiencing the implications of greed - affect subsequent behavior in the CPR dilemma.

\section{Study 3 Methods}

\section{Participants and design}

82 students from a Southwestern US University (32\% male; $\left.M_{\text {age }}=21\right)$ participated. None participated in Studies 1 or 2 . Sessions lasted approximately 30 minutes ( $\left.M_{\text {earnings }}=\mathrm{US} \$ 14.57\right)$.

\section{Procedure}

Participants were randomly assigned to a computer and instructed about a previous CPR dilemma that took place between two participants in a past experimental session; these instructions about the CPR dilemma where similar to those provided to participants in Studies 1 and 2. We then informed participants about the withdrawal of one of the participants in the pair, and asked them to evaluate that decision. They filled-in the same greed questionnaire used in the previous studies. To ensure proper variation, participants were randomly informed of one of following three withdrawals: 5 units (greedy), 3 units (moderate), or 1 unit (not greedy). 


\section{RUNNING HEAD: IS GREED CONTAGIOUS?}

After participants evaluated the previous participant’s greed (based on the revealed withdrawal level), they participated in one round of the CPR dilemma themselves. The specific procedures from this point mirrored those of Studies 1 and 2. At the time participants evaluated the former participant, they did not know they would be participating in the CPR dilemma themselves; thus their greed perceptions we elicited independently of their own plans of behavior.

\section{Results}

We first check that participants evaluated higher withdrawals of the previous participant as greedier. The average greed evaluations of the previous participant (ranging from $1=$ not at all greedy to $7=$ extremely greedy) for each of the three possible withdrawals were $M_{5 \text { units }}=5.15 ; M_{3}$ units $=2.86 ; M_{1 \text { unit }}=$ 2.35. There is strong correlation between the revealed withdrawal and the participant's greed evaluation ( $r$ $=.67, p<.001)$, which is consistent with Study 1 .

[Figure 7]

Next, we examine if participants' own withdrawal in the subsequent CPR dilemma is affected by their greed evaluation of the previous participant. Figure 7 shows the average own withdrawal for each of the possible greed evaluations. There is very little relation between a participant's greed evaluation and their own withdrawal behavior. The correlation between the two is not statistically significant $(r=-.12 ; p=$ .284). Similarly, a regression of a participants' own withdrawal on their greed evaluation yields an insignificant coefficient (with and without controlling for the revealed withdrawal).

\section{Discussion}

Studies 1 and 2 provided evidence that greed perceptions formed in R1 had little direct effect on withdrawals in R2. However, in both studies, greed perceptions were formed based on a participant's personal exposure to the greedy behavior of their opponent. In Study 3, we remove the experience of greedy behavior by having participants form perceptions of a participant in a previous interaction that they were not a part of, essentially shutting-down the possibility of paying greed forward.

Consistent with the two previous studies, we find evidence that greed perceptions affect behavior. When participants observe a high withdrawal by another in a previous interaction, they do perceive that behavior 


\section{RUNNING HEAD: IS GREED CONTAGIOUS?}

as greedy, but there is no relation between their greed perceptions and their own withdrawal. There is, again, no evidence of a direct link between greed perceptions and subsequent behavior.

Neither forming one’s own evaluation of an opponent's earlier greed (Studies 1 and 3), nor receiving such an evaluation from another person (Study 2), seem to have any discernable effect on later withdrawal choices. Participants appear to ignore perceptions of their opponent's greed, but what of perceptions conveyed directly to them about their own greed? We examine this in Study 4.

\section{Study 4: Others’ Perceptions of Own Greed and Contagion of Greedy Behavior}

In the preceding studies, we examined the greed contagion when interacting with: (i) an opponent whose greed was assessed earlier by oneself, or (ii) an opponent whose reputation for greed had been reported by another. In Study 4, we examine the effects of learning another's assessment of one's own greed on one's future withdrawal. Centrally, do participants withdraw less when informed that others see them as greedy?

Social approval research shows that people prefer being viewed positively (Ariely, Bracha \& Meier, 2009; Lacetera \& Macis, 2010; Masclet, Noussair, Tucker \& Villeval, 2003; Noussair \& Tucker, 2005; Pan \& Houser, 2017; Rege \& Telle, 2004). Since greed is generally socially disapproved (Grégroire et al., 2010; Haynes, et al., 2017; Wang \& Murnighan, 2011), learning that an opponent sees one’s R1 behavior as greedy should motivate less greedy behavior in R2. The impression management literature also suggests that individuals work to maintain a positive impression (Schlenker, 1980; Greenberg, 1990). Social approval and impression management are driven by the motive of self-enhancement; people are biased toward receiving positive feedback (Baumeister, 1998). As such, they act in ways that portray themselves in a positive light (Murnighan, Oesch \& Pillutla, 2001), supporting the notion that if an individual is perceived as greedy, they will work to change that impression.

Research on internal accountability suggests that people restrain themselves from behavior that causes harm to another when they feel personally responsible (Molenmaker, de Kwaadsteniet \& van Dijk, 2016; Schlenker, Britt, Pennington, Murphy \& Doherty, 1994; Shafir, Simonson \& Tversky, 1993). To the extent that being seen as greedy signals that one has harmed another, participants may feel accountable, and restrain themselves from future greedy actions. Taken together, this suggests that participants will withdraw 


\section{RUNNING HEAD: IS GREED CONTAGIOUS?}

less if their opponent sees them as greedy. Once again, we view perceived greed as an important link between early and subsequent withdrawals and hypothesize a negative relationship between another's perception of one’s own greed in R1 and one’s own subsequent withdrawals in R2 (Hypothesis 9).

\section{Study 4 Methods}

\section{Participants}

176 students from a Southwestern US University (59\% male; $\left.M_{\text {age }}=21.35\right)$ participated. None participated in previous studies. Sessions lasted approximately 45 minutes with $M_{\text {earnings }}=$ US\$14.50.

\section{Procedure}

The procedure of Study 4 followed that of Study 1 with the following modification: after completing R1 and the associated questionnaire, and before R2, participants were told how greedy their opponent perceived them to be in R1:

At the end of TASK 1, the OTHER PLAYER rated your level of greed on a scale from 1 (not at all greedy) to 7 (very greedy).

The OTHER PLAYER reported that your level of greed in TASK 1 was [X] out of 7. ${ }^{7}$

Finally, after R2, participants completed a short questionnaire, which included an evaluation of their own greed in R1 and R2.

\section{Results}

\section{Consistency between another's and one's own greed perceptions}

It is plausible that participants react only to information that they view as reasonable. We therefore examine the relationship between participants' own evaluations of their greed and their opponents' evaluations of how greedy they were in R1. Overall, we find no systematic differences between a participant's selfreported evaluation of their own greed and their opponent's evaluation of how greedy they were.

\footnotetext{
${ }^{7}$ We used two variations of this manipulation. In condition 1 both participants in a pair were informed of their own greed rating, and both knew this information would be shared. In condition 2, only one participant was given this information; A knew B's rating of him and also knew that B does not know A's rating of him. However, the data showed little difference in R1 behavior between the two conditions, and no statistically significant differences between conditions in how participants react in R2. We therefore pooled the data across conditions and report here only the results from the pooled sample. Note, the 43 participants in Condition 2 who received no feedback are informationally equivalent to the participants from Study 1 and are therefore incorporated into the Study 1 sample (see footnote 4).
} 


\section{RUNNING HEAD: IS GREED CONTAGIOUS?}

Withdrawals by participants in R1 correlated strongly with both self-reported ratings of one's own greed ( $r$ $=.71, p<.01)$, and with opponents' ratings of perceived greed. $(r=.73, p<.01)$. We found no evidence of self-serving bias (Schilizzi \& Iftekhar, 2015; Ubeda, 2013); the data showed no overall difference between one's own and one's opponent's rating of the greed of one's R1 withdrawals $(M=3.80$ and $M=3.63$ respectively; $t(132)=.883, p=.38)$. Figure 8 shows the distribution of the difference between the two ratings. In 59/133 (44\%) instances there was no difference, and in 94/133 (71\%) instances the difference was no more than 1 point.

\section{[Figure 8]}

\section{Participants' reactions to being perceived as greedy}

Next, we examined if participants’ R2 withdrawal is affected by how greedy their opponent perceived them to be in R1. Table 4 presents several regressions of own withdrawal R2 on withdrawal in R1 and perceived greed from R1. Of primary interest is whether an opponent's rating of the focal participant's greed in R1 (own greed R1) affects the focal participant's subsequent own withdrawal R2. We proposed that if the focal participant received high ratings of perceptions of their own greed in conjunction with their R1 withdrawal, they would adjust their R2 withdrawal downward (H9). Results showed that both own withdrawal R1 and opponent withdrawal R1 predicted own withdrawal R2 (Column 1). Adding own greed $R 1$ to the model (Columns 2-5) did little to improve it, rejecting Hypothesis 9. The results also show that the coefficient of perceived opponent greed R1 (Columns 3-4) was not significant, and adding this measure to the model did not explain additional variance. In short, there is no evidence that greed perceptions related to R1 behavior, either one’s own or one’s opponent's, were predictive of R2 withdrawals.

\section{[Table 4]}

\section{Discussion}

Study 4 explored another mechanism by which withdrawal in R1 might be linked to withdrawal in R2 - by opponents' assessments of how greedy participants' initial withdrawals were. We hypothesized that learning an opponent rated one's behavior as greedy would reduce one's withdrawal in R2. We grounded this hypothesis in the social approval, impression management and internal accountability literatures. 


\section{RUNNING HEAD: IS GREED CONTAGIOUS?}

Interestingly, opponent's ratings were broadly consistent with self-ratings, with no evidence of self-serving bias; yet we found no effect of own or other's greed ratings on R2 withdrawals. Once again, participants judged large R1 withdrawals as greedy, but these perceptions did not affect subsequent withdrawals. It was participants’ and opponents’ R1 behavior, and not greed perceptions, that determined R2.

\section{General Discussion}

Our primary goal was to examine behavioral reactions to greed perceptions in social interactions, and determine the extent to which there is greed contagion; namely, whether perceptions of other's greed directly result in individuals acting in a greedier manner themselves. In four studies, we examined how individuals: (i) respond when interacting with another whom they judge as greedy; (ii) respond when interacting with another who has a reputation of being greedy;(iii) respond to exposure to greedy behavior by unrelated others; and (iv) react to being perceived as greedy.

Our findings suggest that greedy behavior does spillover into subsequent interactions. However, the novelty lies in the somewhat paradoxical finding that greed perceptions are not the mechanism driving this contagion. In that sense, we fail to document evidence of greed contagion. Rather, greed perceptions appear to be epiphenomenal. The important distinction differentiates what the participant does - how much is withdrawn- and another's assessment of how greedy this withdrawal is. Greed perceptions were consistently related to high withdrawals, but did not mediate the relationship between high initial opponent withdrawals and increases in focal participants' subsequent withdrawals when interacting against the same opponent. In a stricter test, we paired incumbent participants with new participants in R2 and again found behavioral spillover, but no behavioral reactions to greed perceptions. This suggests that we need to reconceptualize our understanding of the role greed perceptions play in dynamic interactions.

Furthermore, the epiphenomenal nature of greed perceptions seem robust. Greed perceptions are important; if an individual takes a lot of resources at the expense of others, that person is perceived as greedy. Even participants' own greed ratings were aligned with other's ratings of their greed, and were positively related to the amounts withdrawn. Yet, it does not seem to matter if one becomes aware of past instances of greed, perceives their opponent as greedy, if a third party perceives one's opponent as greedy, 


\section{RUNNING HEAD: IS GREED CONTAGIOUS?}

or if a focal participant is presented with their opponent's ratings of their own greed - these perceptions of greed do not drive subsequent behavior for either the participant or the opponent above previous behaviors. Those who were perceived as greedy continued to withdraw high amounts, with little regard for their own or others' assessments of their greed.

Behavior in CPR dilemmas can be shaped by different motivations such as reciprocity, punishment, and norm learning. In examining greed contagion, it is necessary to do so under the backdrop of other motivations. Given that we find little evidence that greed perceptions affect subsequent behavior (after controlling for observed behavior), this suggests that other motivations may be more dominant. In Study 1 participants interacted with the same opponent, so reciprocity or punishment motives could crowd-out greed contagion. However, in Study 2 we effectively eliminated this channel, by having participants interact in R2 with a different opponent. We still observe spillover in withdrawal from initial rounds. The data suggest that norm-learning is important - people learn what behavior is acceptable/expected (in this environment that might be unfamiliar), and then apply that to subsequent interactions (Gino et al., 2009a; Gino et al., 2009b; Pillutla \& Chen, 1999). The behavioral spillover pattern is also consistent with individuals "paying it forward” (Gray et al., 2014), after having been the victim of greedy behavior, although study 3 shows that merely learning how unrelated others behave in the task does not affect behavior.

Our results contradict evidence that reputation shapes respondent behavior (Brandt et al., 2003; Duffy \& Felovich, 2002). Specifically, when participants received information about their opponent's past greed (based on another's evaluation) with little context and no direct experience, this information had little impact on their behavior. Despite the reliable nature of the "pure" greed reputations presented to new participants, it is possible that the consequences of garnering a greedy reputation may be muted when information about earlier decisions and greedy behavior is not transparent. We considered a generalized reputation construct that captures the propensity to behave in a certain way outside of a known domain. In most of the reputation management literature, reputation refers to a history of past behavior in a specific domain. This distinction may be important; namely, while we do observe evidence of history of past behavior of one's opponent influencing behavior, we find little evidence of a behavioral reaction when 


\section{RUNNING HEAD: IS GREED CONTAGIOUS?}

participants only received information about their opponent's greed reputation unaware of the specific behavior that garnered the reputation. The lack of context may have reduced participants' confidence in the information given to them, and weakened their reaction to the reputation information.

Our results also suggest that one's self-impression is not tarnished by being perceived as greedy. Participants ignored potential effects that a greedy reputation may have, showed no evidence of managing their greed reputation, even when informed that it would be shared. Contrary to the literature on social approval and impression management, our results suggest that being viewed as greedy might not carry the same stigma as other behaviors like lying, cheating and being unfair.

Other important implications emerged from our findings. While some paired participants were able to successfully achieve a cooperative outcome, these outcomes were fragile, following Pillutla and Chen's (1991) findings. We found that competitive, tit-for-tat outcomes were more robust (Fischbacher \& Gächter, 2010). Even the seemingly tangential behavior of others acting in pursuit of their own self-interest can cause overall cooperation to fall apart. As Gino et al. (2009a) suggest, one bad apple can indeed ruin the barrel. Our results point toward the difficulty of turning a group toward an overall cooperative outcome. The robust nature of competitive decisions suggests that once behavior has escalated to a highly competitive state, cooperative attempts by a few select members will likely not be sufficient to motivate competitive group members to start cooperating (Bettenhausen \& Murnighan, 1991).

Our findings are, subject to the familiar limitations of laboratory studies: Student performing brief, unfamiliar tasks for modest financial incentives and with little opportunity to learn. Moreover, in all three studies reported we utilized a CPR dilemma; hence, there it is possible that our main results do not generalize to other settings where greed perceptions might be salient. We do, however, see a role for such studies in early-stage theory development. We examine greed contagion using a CPR dilemma because of its ability to incite strong greed perceptions. That said, there are important questions that remain to be explored in follow-up research. For example, do we see the same lack of greed contagion in other setting? Why do people not react to their perceptions of other's greed? In which settings are people more negative to the greed of others and, hence, more inclined to react on their perceptions? 


\section{RUNNING HEAD: IS GREED CONTAGIOUS?}

\section{Conclusion}

The importance of investigating possible reactions to behavior perceived as greedy is apparent. The tension between cooperative and self-interested motives inherent in a CPR dilemma makes it a clear platform for studying greed perceptions and behavioral reactions to those perceptions. Interestingly, our data demonstrates a strong relationship between acquisitive behavior and greed perceptions, yet no contagion effect of greed perceptions on behavior. In particular, participants do not appear to behave differently in reaction to perceptions of another's greed or another's greedy reputation. In short, within the constraints of the specific paradigm used here, perceived greed appears to be driven by a consistent set of antecedents; it just does not have much of an effect on how individuals behave over the direct reaction to past behavioral outcomes. While norms of selfish behavior are contagious, it is not the perceptions of greed that are necessarily the cause of this contagion. 


\section{RUNNING HEAD: IS GREED CONTAGIOUS?}

\section{References}

Ahn, T. K., Ostrom, E., Schmidt, D., Shupp, R., \& Walker, J. (2001). Cooperation in PD games: Fear, greed, and history of play. Public Choice, 106(1-2), 137-155.

Aloise-Young, P. A. (1993). The development of self-presentation: Self-promotion in 6-to 10- year-old children. Social Cognition, 11(2), 201-222.

Anderson, J. (2014). Selfish, excessive, greedy: The psychological causes and consequences of perceptions of greed. Unpublished dissertation, The University of Arizona: Tucson, AZ.

Ariely, D., Bracha, A., \& Meier, S. (2009). Doing good or doing well? Image motivation and monetary incentives in behaving prosocially. American Economic Review, 99, 544-555.

Ausick, P. (2010, February 1). Another shameful bonus at Goldman Sachs? It's hard to imagine a more tone-deaf move, but Goldman's chief executive is reportedly set to receive a $\$ 100$ million bonus. To Stocks - MSN Money.

Battigalli, P., \& Dufwenberg, M. (2007). Guilt in Games. American Economic Review 97, 170 - 176.

Battigalli, P., Dufwenberg, M., \& Smith, A. (2015). Frustration and Anger in Games. CESifo Working Paper No. 5258.

Baumeister, R. F. (1998). The Self. In D. T. Gilbert, S. T. Fiske, and G. Lindzey (Eds.), The Handbook of Social Psychology 4th Ed. (pp. 680-740). New York: McGraw-Hill.

Baumeister, R. F., Bratslavsky, E., Finkenauer, C., \& Vohs, K. D. (2001). Bad is stronger than good. Review of General Psychology, 5(4), 323.

Bettenhausen, K., \& Murnighan, J. K. (1985). The emergence of norms in competitive decision-making groups. Administrative Science Quarterly, 30(3), 350-372.

Bettenhausen, K. L., \& Murnighan, J. K. (1991). The development of an intragroup norm and the effects of interpersonal and structural challenges. Administrative Science Quarterly, 36(1), 20-35.

Bies, R.J., \& Tripp, T.M. (1996). Beyond trust: “Getting even” and the need for revenge. In R.W. Griffin, A. O’Leary-Kelly, \& J.M. Collins (Eds.), Trust in Organizations (pp. 246-260). Newbury Park, CA: Sage.

Birenbaum, A., \& Sagarin, E. (1976). Norms and human behavior. New York: Praeger Publishers.

Bohnet, I., \& Huck, S. (2004). Repetition and reputation: Implications for trust and trustworthiness when institutions change. American Economic Review, 94, 362-366.

Boles, T. L., Croson, R. T., \& Murnighan, J. K. (2000). Deception and retribution in repeated ultimatum bargaining. Organizational Behavior and Human Decision Processes, 83(2), 235-259.

Bolton, G., Greiner, B., \& Ockenfels, A. (2013). Engineering trust: reciprocity in the production of reputation information. Management Science, 59(2), 265-285.

Bolton, G. E., Katok, E., \& Ockenfels, A. (2004). How effective are electronic reputation mechanisms? An experimental investigation. Management Science, 50, 1587-1602.

Bolton, G. E., Katok, E., \& Ockenfels, A. (2005). Cooperation among strangers with limited information about reputation. Journal of Public Economics, 89, 1457-1468.

Bosman, R., Sutter, M., \& van Winden, F. (2005). The impact of real effort and emotions in the power-totake game. Journal of Economic Psychology 26, 407-429. 


\section{RUNNING HEAD: IS GREED CONTAGIOUS?}

Bosman, R., \& Van Winden, F. (2002). Emotional hazard in a power-to-take experiment. The Economic Journal 112, 147-169.

Brandt, H., Hauert, C., \& Sigmund, K. (2003). Punishment and reputation in spatial public goods games. Proceedings of the Royal Society of London B: Biological Sciences, 270(1519), 1099-104.

Brandts, J., \& Cooper, D. J. (2006a). A Change Would Do You Good...An Experimental Study on How to Overcome Coordination Failure in Organizations. American Economic Review, 96(3), 669-693.

Brandts, J., \& Cooper, D. J. (2006b). Observability and overcoming coordination failure in organizations: An experimental study. Experimental Economics, 9(4), 407-423.

Brebels, L., De Cremer, D., \& Sedikides, C. (2008). Retaliation as a response to procedural unfairness: A self-regulatory approach. Journal of Personality and Social Psychology, 95(6), 1511-1525.

Carnevale, J. B., Walker, A. G., \& Walker, H. J. (2016). Organizational Greed: Behavior, Perception, or Trait? Toward an Integrated Theory. In Academy of Management Proceedings (Vol. 2016, No. 1, p. 11480). Academy of Management.

Cason, T. N., Savikhin, A. C., \& Sheremeta, R. M. (2012). Behavioral spillovers in coordination games. European Economic Review, 56(2), 233-245.

Charness, G., Du, N., \& Yang, C. L. (2011). Trust and trustworthiness reputations in an investment game. Games and Economic Behavior, 72, 361-375.

Chaudhuri, A. (2011). Sustaining cooperation in laboratory public goods experiments: a selective survey of the literature. Experimental Economics, 14, 47-83.

Cialdini, R.B., Reno, R.R., \& Kallgren (1990). A focus theory of normative conduct: Recycling the concept of norms to reduce littering in public places. Journal of Personality and Social Psychology, 58, 10151026.

Collier, P. (2000). Rebellion as a quasi-criminal activity. Journal of Conflict Resolution, 44, 839-853.

Collier, P., \& Hoeffler, A. (1998). On economic causes of civil war. Oxford Economic Papers, 50(4), 563573.

Colquitt, J. A., Scott, B. A., Rodell, J. B., Long, D. M., Zapata, C. P., Conlon, D. E., \& Wesson, M. J. (2013). Justice at the millennium, a decade later: A meta-analytic test of social exchange and affectbased perspectives. Journal of Applied Psychology, 98(2), 199-236.

Colvin, G. (2006, June). A study in CEO greed. Fortune 153, 53. Retrieved from http://archive.fortune.com/magazines/fortune/fortune_archive/2006/06/12/8379243/index.htm

Croson, R., Fatas, E., \& Neugebauer, T. (2005). Reciprocity, matching and conditional cooperation in two public goods games. Economics Letters, 87, 95-101.

Crossley, C. D. (2009). Emotional and behavioral reactions to social undermining: A closer look at perceived offender motives. Organizational Behavior and Human Decision Processes, 108, 14-24.

Dawes, C. T., Fowler, J. H., Johnson, T., McElreath, R., \& Smirnov, O. (2007). Egalitarian motives in humans. Nature 446, 794-796.

Deutsch, M. (1975). Equity, equality, and need: What determines which value will be used as the basis of distributive justice? Journal of Social Issues, 31(3), 137-149.

Dorfman, J. (2013, December 15). Workers Should Be Very Thankful That Corporations Are So Greedy. Retrieved from http://www.forbes.com/sites/jeffreydorfman/2013/12/15/corporate- greed-is-notselective-so-it-cannot-hold-down-wages/\#6c5b60bb4bcd 


\section{RUNNING HEAD: IS GREED CONTAGIOUS?}

Duffy, J., \& Feltovich, N. (2002). Do actions speak louder than words? An experimental comparison of observation and cheap talk. Games and Economic Behavior, 39, 1-27.

Dufwenberg, M. \& Kirchsteiger, G. (2004). A Theory of Sequential Reciprocity. Games and Economic Behavior 47, 268 - 298.

Dulleck, U., Kerschbamer, R., \& Sutter, M. (2011). The Economics of Credence Goods: An Experiment on the Role of Liability, Verifiability, Reputation, and Competition. American Economic Review 101, 526-555.

Elster, J. (1998). Emotions and economic theory. Journal of Economic Literature 36, 47-74.

Engel, D., \& Zhurakhovska, L. (2016). When is the risk of cooperation worth taking? The prisoner's dilemma as a game of multiple motives. Applied Economics Letters, 23, 1157-1161.

Engelmann, D., \& Fischbacher, U. (2009). Indirect reciprocity and strategic reputation building in an experimental helping game. Games and Economic Behavior, 67, 399-407.

Engelmann, J. M., Herrmann, E., \& Tomasello, M. (2012). Five-year olds, but not chimpanzees, attempt to manage their reputations. PLoS One, 7(10).

Falk, A., \& Fischbacher, U. (2006). A theory of reciprocity. Games and Economic Behavior 54, 293-315.

Fehr, E. (2004). Human behaviour: Don't lose your reputation. Nature, 432(7016), 449-450.

Fehr, E., \& Fischbacher, U. (2004a). Third-party punishment and social norms. Evolution and Human Behavior, 25(2), 63-87.

Fehr, E., \& Fischbacher, U. (2004b). Social norms and human cooperation. Trends in Cognitive Sciences, 8(4), 185-190.

Fischbacher, U. (2007). z-Tree: Zurich toolbox for ready-made economic experiments. Experimental Economics, 10(2), 171-178.

Fischbacher, U., \& Gächter, S. (2010). Social Preferences, Beliefs, and the Dynamics of Free Riding in Public Goods Experiments. American Economic Review, 100, 541-556.

Fischbacher, U., Gächter, S., \& Fehr, E. (2001). Are people conditionally cooperative? Evidence from a public goods experiment. Economics Letters, 71, 397-404.

Frey, B. S., \& Meier, S. (2004). Social comparisons and pro-social behavior: Testing “conditional cooperation” in a field experiment. American Economic Review, 94, 1717-1722.

Gächter, S. (2007). Conditional Cooperation: Behavioral Regularities from the Lab and the Field and Their Policy Implications. In B. Frey \& A. Stutzer (Eds.), Psychology and Economics: A Promising New Cross-Disciplinary Field (CESifo Seminar Series) (pp 19-50). Cambridge: The MIT Press.

Gardner, R., Ostrom, E., \& Walker, J. M. (1990). The nature of common-pool resource problems. Rationality and Society 2, 335-358.

Gilliland, S.W., \& Anderson, J.S. (2011). Perceptions of greed: A distributive injustice model. In S.W. Gilliland, D.D. Steiner, \& D.P. Skarlicki (Eds.), Emerging Perspectives on Organizational Justice and Ethics: Research in Social Issues in Management. Information Age Press: Charlotte, NC.

Gino, F., Ayal, S., \& Ariely, D. (2009a). Contagion and differentiation in unethical behavior the effect of one bad apple on the barrel. Psychological Science, 20(3), 393-398.

Gino, F., Gu, J., \& Zhong, C. B. (2009b). Contagion or restitution? When bad apples can motivate ethical behavior. Journal of Experimental Social Psychology, 45(6), 1299-1302. 


\section{RUNNING HEAD: IS GREED CONTAGIOUS?}

Gray, K., Ward, A. F., \& Norton, M. I. (2014). Paying it forward: generalized reciprocity and the limits of generosity. Journal of Experimental Psychology: General, 143(1), 247.

Greenberg, J. (1990). Looking fair vs. being fair: Managing impressions of organizational justice. Research in Organizational Behavior, 12, 111-158.

Greenberg, J. (1993). Stealing in the name of justice: Informational and interpersonal moderators of theft reactions to underpayment inequity. Organizational Behavior and Human Decision Processes 54, 81103.

Grégoire, Y., Laufer, D., \& Tripp, T. M. (2010). A comprehensive model of customer direct and indirect revenge: understanding the effects of perceived greed and customer power. Journal of the Academy of Marketing Science, 38, 738-758.

Gunnthorsdottir, A., Houser, D., \& McCabe, K. (2007). Disposition, history and contributions in public goods experiments. Journal of Economic Behavior \& Organization, 62, 304-315.

Hardin, G. (1968). The Tragedy of the Commons. Science, 162, 1243-1248.

Haynes, K.T., Campbell, J.T. \& Hitt, M.A. (2017). When more is not enough: Executive greed and its influence on shareholder wealth. Journal of Management, 43(2), 555-584.

Haynes, K. T., Hitt, M.A., \& Campbell, J.T. (2015). The dark side of leadership: Towards a mid-range theory of hubris and greed in entrepreneurial contexts. Journal of Management Studies,52(4), $\quad$ 479505.

Henrich, J., McElreath, R., Barr, A., Ensminger, J., Barrett, C., Bolyanatz, A., Cardenas, J.C., Gurven, M., Henrich, N., \& Lesorogol, C. (2006). Costly punishment across human societies. Science, 312(5781), 1767-1770.

Jones, D. A., \& Skarlicki, D. P. (2005). The effects of overhearing peers discuss an authority's fairness reputation on reactions to subsequent treatment. Journal of Applied Psychology, 90(2), 363-372.

Keysar, B., Converse, B. A., Wang, J., \& Epley, N. (2008). Reciprocity is not give and take: Asymmetric reciprocity to positive and negative acts. Psychological Science, 19(12), 1280-1286.

Knez, M., \& Camerer, C. (2000). Increasing cooperation in prisoner's dilemmas by establishing a precedent of efficiency in coordination games. Organizational Behavior and Human Decision Processes, 82(2), 194-216.

Kramer, R.M. (2001). Organizational paranoia: Origins and dynamics. Research in Organizational Behavior, 23, 1-42.

Kugler, T., Connolly, T., \& Ordóñez, L. D. (2012). Emotion, decision, and risk: Betting on gambles versus betting on people. Journal of Behavioral Decision Making 25, 123-134.

Lacetera, N., \& Macis, M. (2010). Social image concerns and prosocial behavior: Field evidence from a nonlinear incentive scheme. Journal of Economic Behavior \& Organization, 76(2), 225-237.

Loewenstein, G. (2000). Emotions in economic theory and economic behavior. American Economic Review 90, 426 - 432.

Loewenstein, G., \& Lerner J. S. (2002). The role of affect in decision making. In R. Davidson, H. Goldsmith, \& K. Scherer (Eds.), Handbook of Affective Science (pp. 619 - 642). Oxford: Oxford University Press.

Lupia, A., McCubbins, M. D., \& Popkin, S. L. (Eds.). (2000). Elements of reason: Cognition, choice, and the bounds of rationality. Cambridge University Press. 


\section{RUNNING HEAD: IS GREED CONTAGIOUS?}

Masclet, D., Noussair, C., Tucker, S., \& Villeval, M. C. (2003). Monetary and nonmonetary punishment in the voluntary contributions mechanism. American Economic Review, 93, 366-380.

McGee, S. (2016, January 7). Bernie Sanders has a problem: sometimes greed is good. Retrieved from https://www.theguardian.com/us-news/us-money-blog/2016/jan/07/bernie-sanders-greed

Milinski, M., Semmann, D., \& Krambeck, H. J. (2002). Reputation helps solve the 'tragedy of the commons'. Nature, 415, 424-426.

Molenmaker, W. E., de Kwaadsteniet, E. W., \& van Dijk, E. (2016). The impact of personal responsibility on the (un) willingness to punish non-cooperation and reward cooperation. Organizational Behavior and Human Decision Processes, 134, 1-15.

Murnighan, J. K., Oesch, J. M., \& Pillutla, M. (2001). Player types and self-impression management in dictatorship games: Two experiments. Games and Economic Behavior, 37(2), 388-414.

Mussel, P., \& Hewig, J. (2016). The life and times of individuals scoring high and low on dispositional greed. Journal of Research in Personality, 64, 52-60.

Nikiforakis, N. (2010). Feedback, punishment and cooperation in public good experiments. Games and Economic Behavior, 68, 689-702.

Noussair, C., \& Tucker, S. (2005). Combining monetary and social sanctions to promote cooperation. Economic Inquiry, 43, 649-660.

Ostrom, E., Dietz, T., Dolsak, N., Stern, P., Stonich, S., \& Weber, E. (2002). The Drama of the Commons. Washington, DC: National Academy Press.

Pan, X., \& Houser, D. (2017). Social Approval, Competition, and Cooperation. Experimental Economics, 20(2), 309-332.

Panchanathan, K., \& Boyd, R. (2004). Indirect reciprocity can stabilize cooperation without the secondorder free rider problem. Nature, 432(7016), 499-502.

Pearlstein, S. (2016, June 3). Challenging the greed-is-good gospel of free markets.

Piazza, J., \& Bering, J. M. (2008). The effects of perceived anonymity on altruistic punishment. Evolutionary Psychology, 6(3), 487-501.

Piazza, J., Bering, J. M., \& Ingram, G. (2011). “Princess Alice is watching you”: Children’s belief in an invisible person inhibits cheating. Journal of Experimental Child Psychology, 109(3), 311-320.

Pillutla, M. M., \& Chen, X. P. (1999). Social norms and cooperation in social dilemmas: The effects of context and feedback. Organizational Behavior and Human Decision Processes, 78(2), 81-103.

Preacher, K. J., \& Hayes, A. F. (2004). SPSS and SAS procedures for estimating indirect effects in simple mediation models. Behavior Research Methods, 36(4), 717-731.

Rabin, M. (1998). Psychology and economics. Journal of Economic Literature 36, 11 - 46.

Rabin, M. (2002). A perspective on psychology and economics. European Economic Review 46, 657-685.

Rege, M., \& Telle, K. (2004). The impact of social approval and framing on cooperation in public good situations. Journal of Public Economics, 88, 1625-1644.

Reuben, E., \& Van Winden, F. (2008). Social ties and coordination on negative reciprocity: The role of affect. Journal of Public Economics 92, 34-53.

Rigdon, M. L., McCabe, K. A., \& Smith, V. L. (2007). Sustaining Cooperation in Trust Games. The Economic Journal, 117, 991-1007. 


\section{RUNNING HEAD: IS GREED CONTAGIOUS?}

Robertson, A. F. (2001). Greed: Gut feelings, growth, and history. Cambridge, UK: Polity.

Samuelson, C. D., Messick, D. M., Rutte, C., \& Wilke, H. (1984). Individual and structural solutions to resource dilemmas in two cultures. Journal of Personality and Social Psychology, 47, 94-104.

Sanfey, A. G., Rilling, J. K., Aronson, J. A., Nystrom, L. E., \& Cohen, J. D. (2003). The neural basis of economic decision-making in the ultimatum game. Science, 300(5626), 1755-1758.

Sarna, D. E. Y. (2010). History of greed: Financial fraud from tulip mania to Bernie Madoff. Hoboken, NJ: Wiley.

Schilizzi, S.G.M. \& Iftekhar, M.S. (2015). Context and self-serving bias in equity choices. In The Proceedings of the Australian Agricultural \& Resource Economics Society/AARES Annual Conference, Rotorua, New Zealand.

Schlenker, B.R. (1980). Impression management: The self-concept, social identity and interpersonal relations. Monterey, CA: Brooks/Cole.

Schlenker, B. R., Britt, T. W., Pennington, J., Murphy, R., \& Doherty, K. (1994). The triangle model of responsibility. Psychological Review, 101(4), 632-652.

Schmidt, D., Shupp, R., Walker, J., Ahn, T. K., \& Ostrom, E. (2001). Dilemma games: game parameters and matching protocols. Journal of Economic Behavior \& Organization, 46(4), 357-377.

Schmidt, D., Shupp, R., Walker, J. M., \& Ostrom, E. (2003). Playing safe in coordination games: The roles of risk dominance, payoff dominance, and history of play. Games and Economic Behavior, 42(2), 281-299.

Seinen, I., \& Schram, A. (2006). Social status and group norms: Indirect reciprocity in a repeated helping experiment. European Economic Review, 50, 581-602.

Servátka, M. (2009). Separating reputation, social influence, and identification effects in a dictator game. European Economic Review, 53(2), 197-209.

Seuntjens, T. G., Zeelenberg, M., Breugelmans, S. M., \& van de Ven, N. (2015a). Defining greed. British Journal of Psychology, 106(3), 505-525.

Seuntjens, T. G., Zeelenberg, M., van de Ven, N., \& Breugelmans, S. M. (2015b). Dispositional greed. Journal of Personality and Social Psychology, 108(6), 917-933.

Shafir, E., Simonson, I., \& Tversky, A. (1993). Reason-based choice. Cognition, 49(1-2), 11-36.

Skarlicki, D. P., \& Folger, R. (1997). Retaliation in the workplace: The roles of distributive, procedural, and interactional justice. Journal of Applied Psychology, 82(3), 434-443.

Tickle, P. (2004). Greed. New York: Oxford University Press.

Ubeda, P. (2013). The consistency of fairness rules. An experimental study. Journal of Economic Psychology, 41, 88-100.

Van Lange, P. A., Joireman, J., Parks, C. D., \& Van Dijk, E. (2013). The psychology of social dilemmas: A review. Organizational Behavior and Human Decision Processes, 120(2), 125-141.

Wang, L., \& Murnighan, J.K. (2011). On Greed. The Academy of Management Annals, 5(1), 279-316.

Wargo, D. T., Baglini, N. A., \& Nelson, K. A. (2010). The new millennium's first global financial crisis: the neuroeconomics of greed, self-interest, deception, false trust, overconfidence and risk perception. Neuroeconomics and the Firm, 78-98. 


\section{RUNNING HEAD: IS GREED CONTAGIOUS?}

Weber, J. M., Kopelman, S., \& Messick, D. M. (2004). A conceptual review of decision making in social dilemmas: Applying a logic of appropriateness. Personality and Social Psychology Review, 8(3), 281-307.

Wilke, H. A. (1991). Greed, efficiency and fairness in resource management situations. European Review of Social Psychology, 2(1), 165-187. 


\section{RUNNING HEAD: IS GREED CONTAGIOUS?}

Figure 1. Perceptions of Greed Associated with R1 Withdrawals (Study 1)

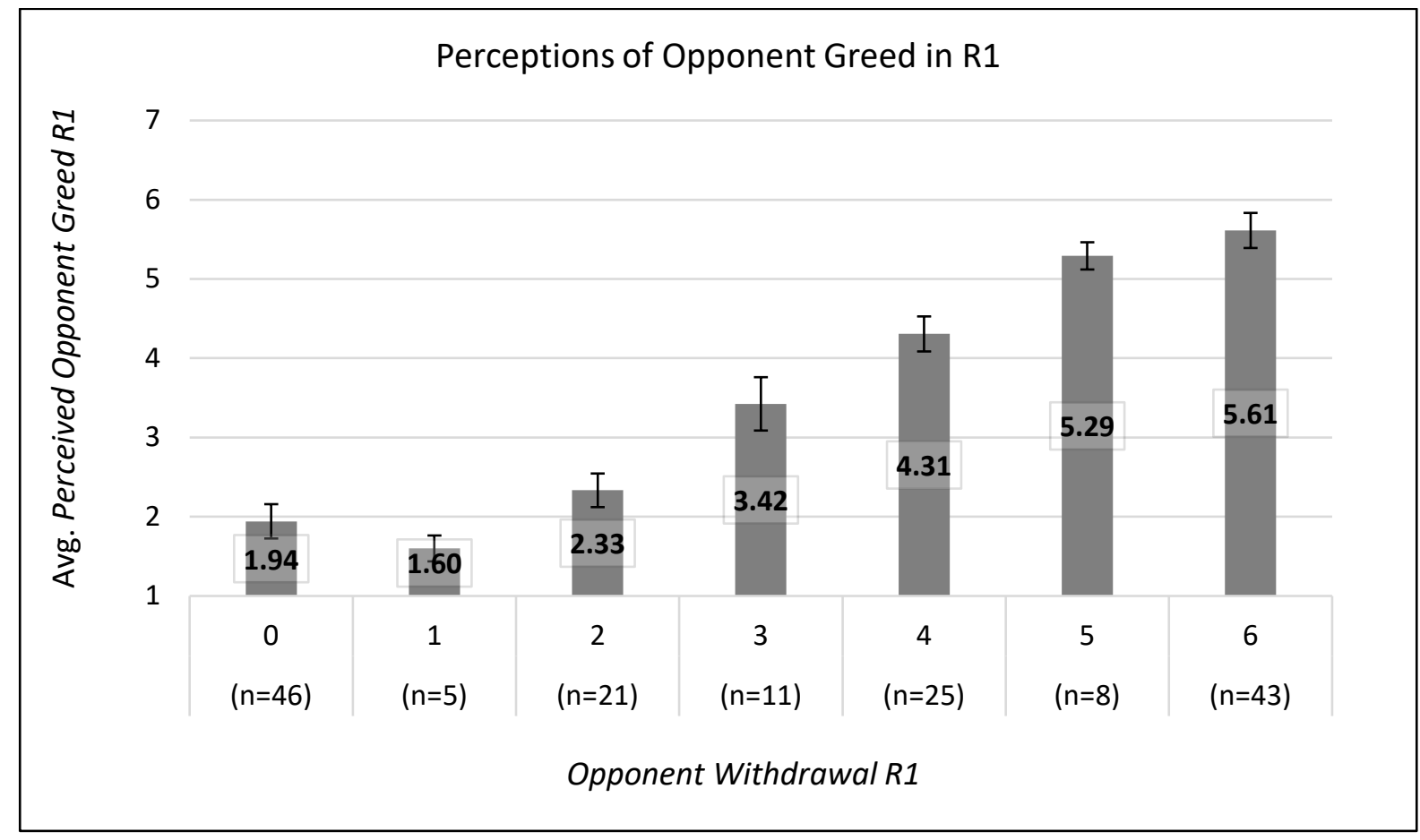

Figure 1. Participants' perceptions of their opponent's greed after withdrawals in round 1 of the CPR dilemma. The numbers immediately below the $\mathrm{x}$-axis indicate the number of units of stock withdrawn by an opponent in round 1. Error bars indicate the standard error. The correlation between opponent withdrawal R1 and participants' perceived opponent greed $R 1$ is $r=.77$ ( $p<$ $.01)$. 
Figure 2. Perceptions of Others' Greed in R1 and Own R2 Withdrawals (Study 1)

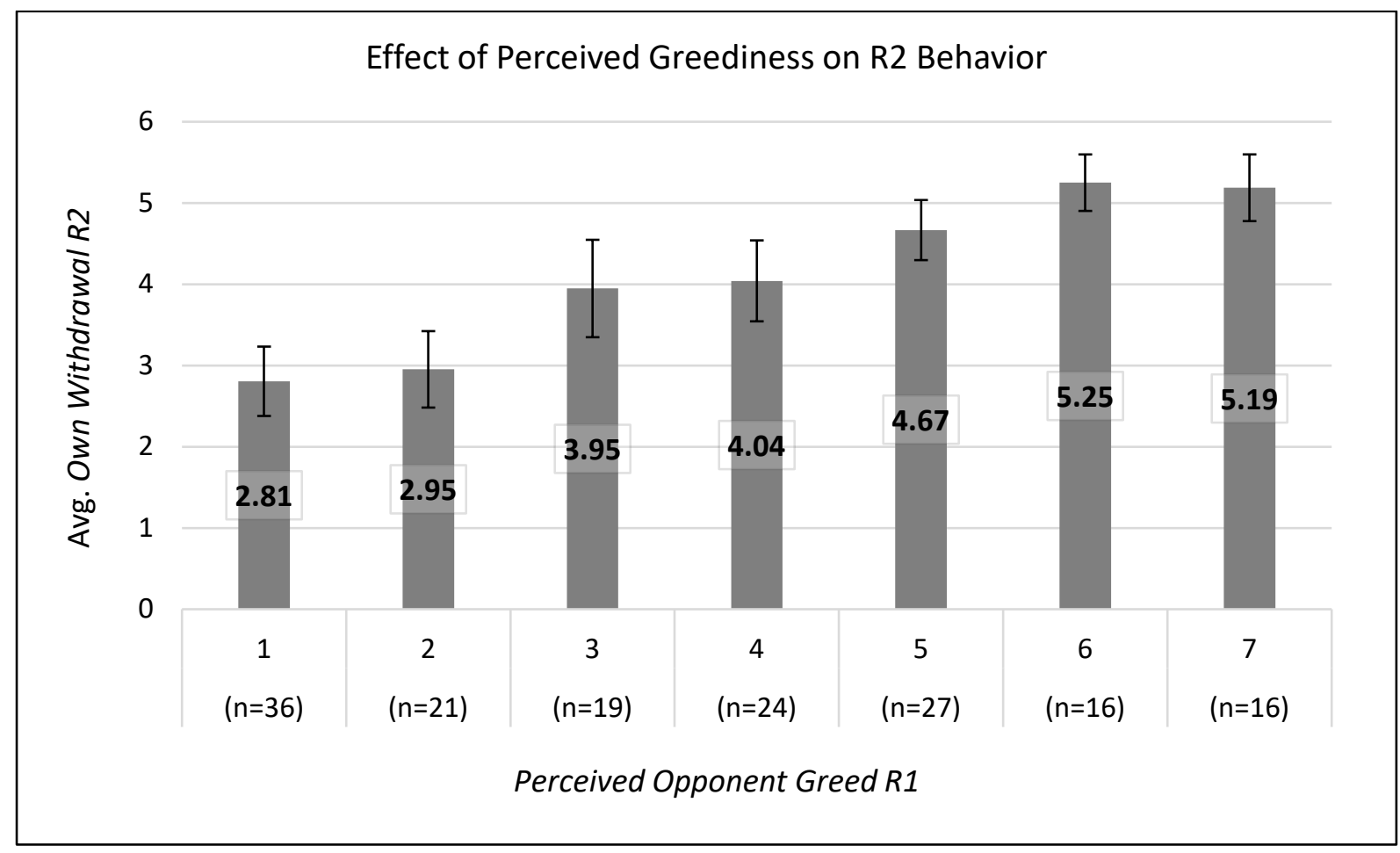

Figure 2. Participants' perceptions of their opponent's greed in round 1 and their subsequent round 2 withdrawals. The numbers immediately below the $\mathrm{x}$-axis indicate the seven possible integer values of a participant's perception of their opponent's greed in round 1. Because the 3-item greed perception scale does not necessarily result in integer values (each item was on a scale from 1 to 7), we rounded greed perceptions to the nearest integer for binning purposes in this figure. Error bars indicate the standard error. The correlation between perceived opponent greed R1 and own withdrawal $R 2$ is $r=.38(p<.01)$. 
Figure 3. Plot of the Compare and Adjust Process from R1 to R2 (Study 1)

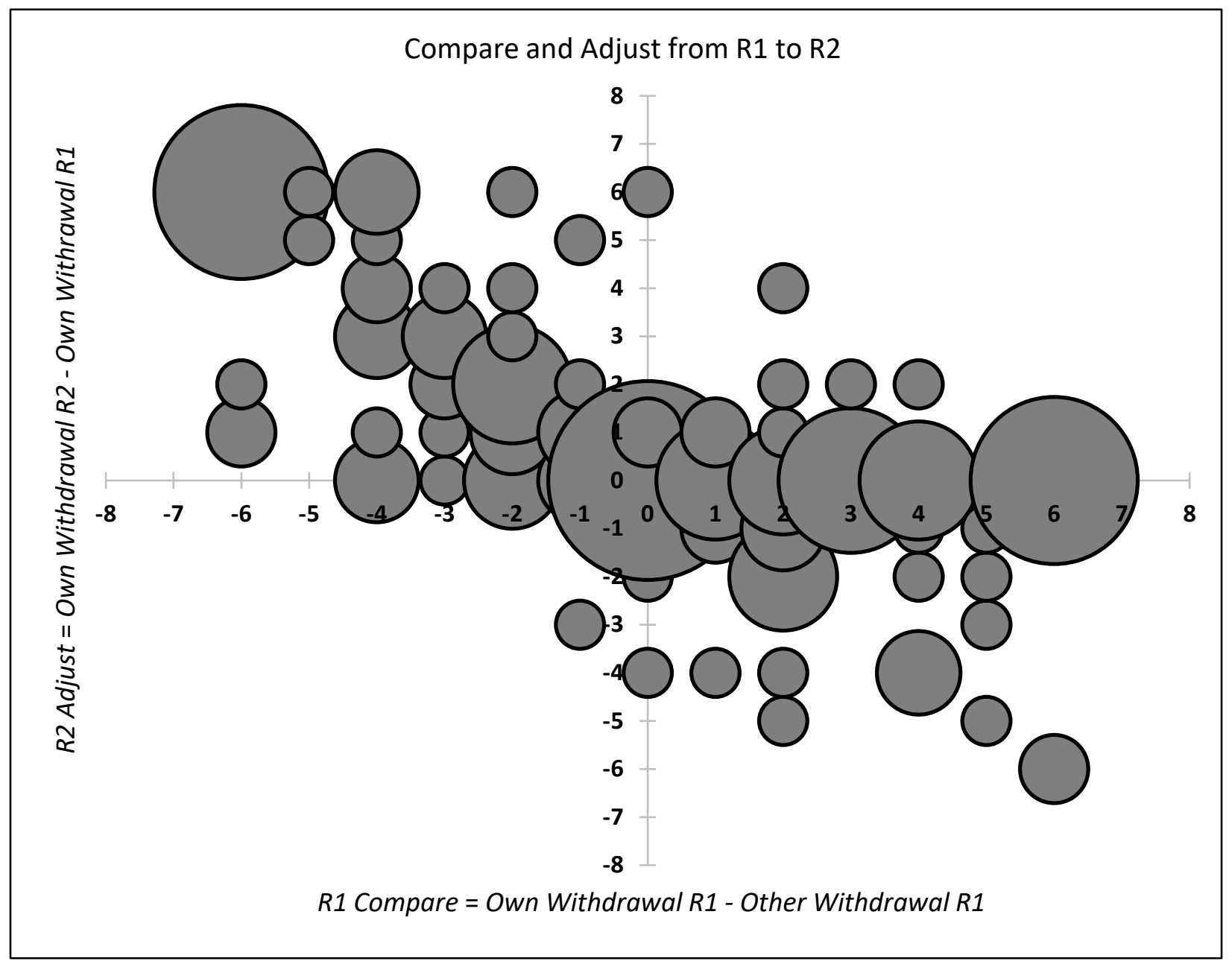

Figure 3. Plot of the compare and adjust process from round 1 to round 2 . The $x$-axis is the comparison of a participant's round 1 withdrawal with the round 1 withdrawal of their opponent: $R 1$ Compare = (own withdrawal R1 - opponent withdrawal R1), and the y-axis is the level of adjustment from round 1 to round 2: $R 2$ Adjust = (own withdrawal $R 2-$ own withdrawal R1). The size of the bubbles are scaled proportionally to the observed frequency of each coordinate. The correlation is $r=-.71(p<.01)$ 
Figure 4. Plot of the Compare and Adjust Process from R1 to R2 (Study 2)

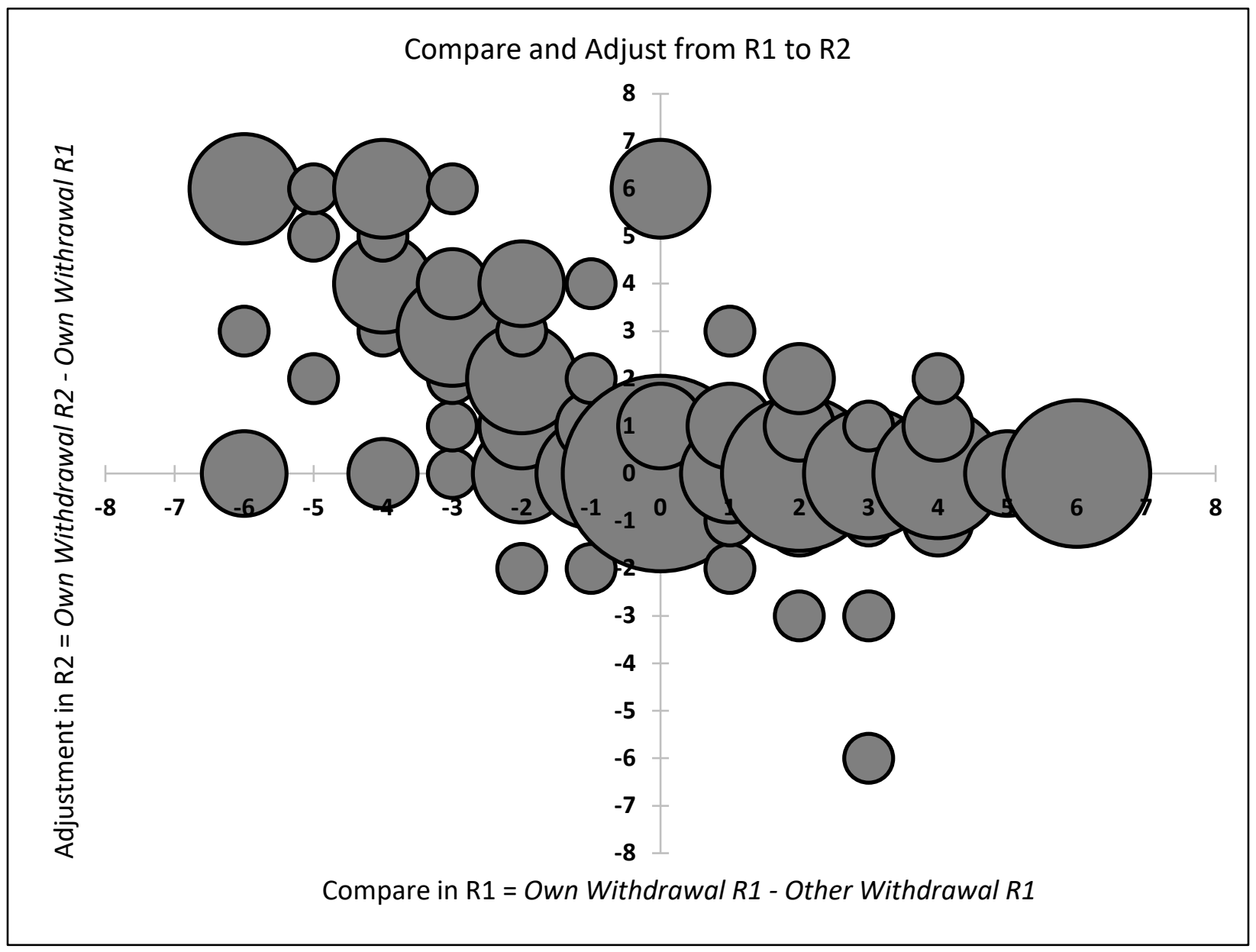

Figure 4. Plot of the compare and adjust process from round 1 to round 2. The $\mathrm{x}$-axis is the comparison of an incumbent participant's round 1 withdrawal with the round 1 withdrawal of their opponent: $R 1$ Compare = (own withdrawal $R 1$ - opponent withdrawal R1), and the $\mathrm{y}$-axis is the level of adjustment from round 1 to round 2: $R 2$ Adjust = (own withdrawal $R 2-$ own withdrawal $R 1$ ). The size of the bubbles are scaled proportionally to the observed frequency of each coordinate. The correlation is $r=-.58(p<.01)$ 


\section{RUNNING HEAD: IS GREED CONTAGIOUS?}

Figure 5. Average New Participant R2 Withdrawals, by Opponent Greed Reputation (Study 2)

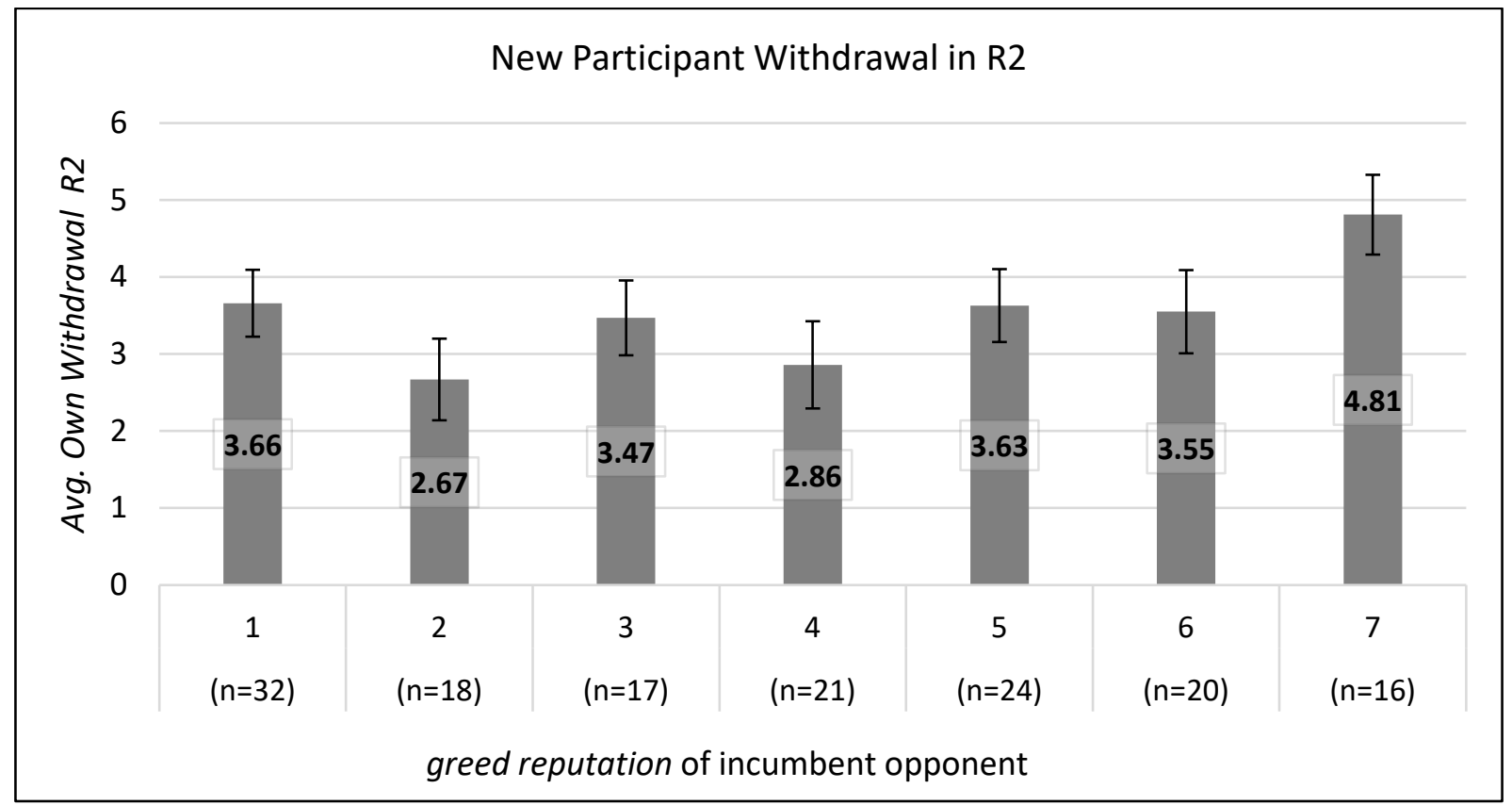

Figure 5. New participants' withdrawals against incumbent opponents whose greed reputation has been conveyed to the new participant. The numbers immediately below the $x$-axis indicate the conveyed perceived greed score of the incumbent opponent, as rated by their first round partner: greed reputation. The y-axis is the average own withdrawal $R 2$ of new participants against incumbent opponents, for each level of greed reputation. Error bars indicate the standard error. The correlation between the opponent's greed reputation and new participants' own withdrawals $R 2$ was $r=.12(p=.15)$. 
RUNNING HEAD: IS GREED CONTAGIOUS?

Figure 6. Incumbent Withdrawals in Warned and Unwarned Reputation Conditions (Study 2)

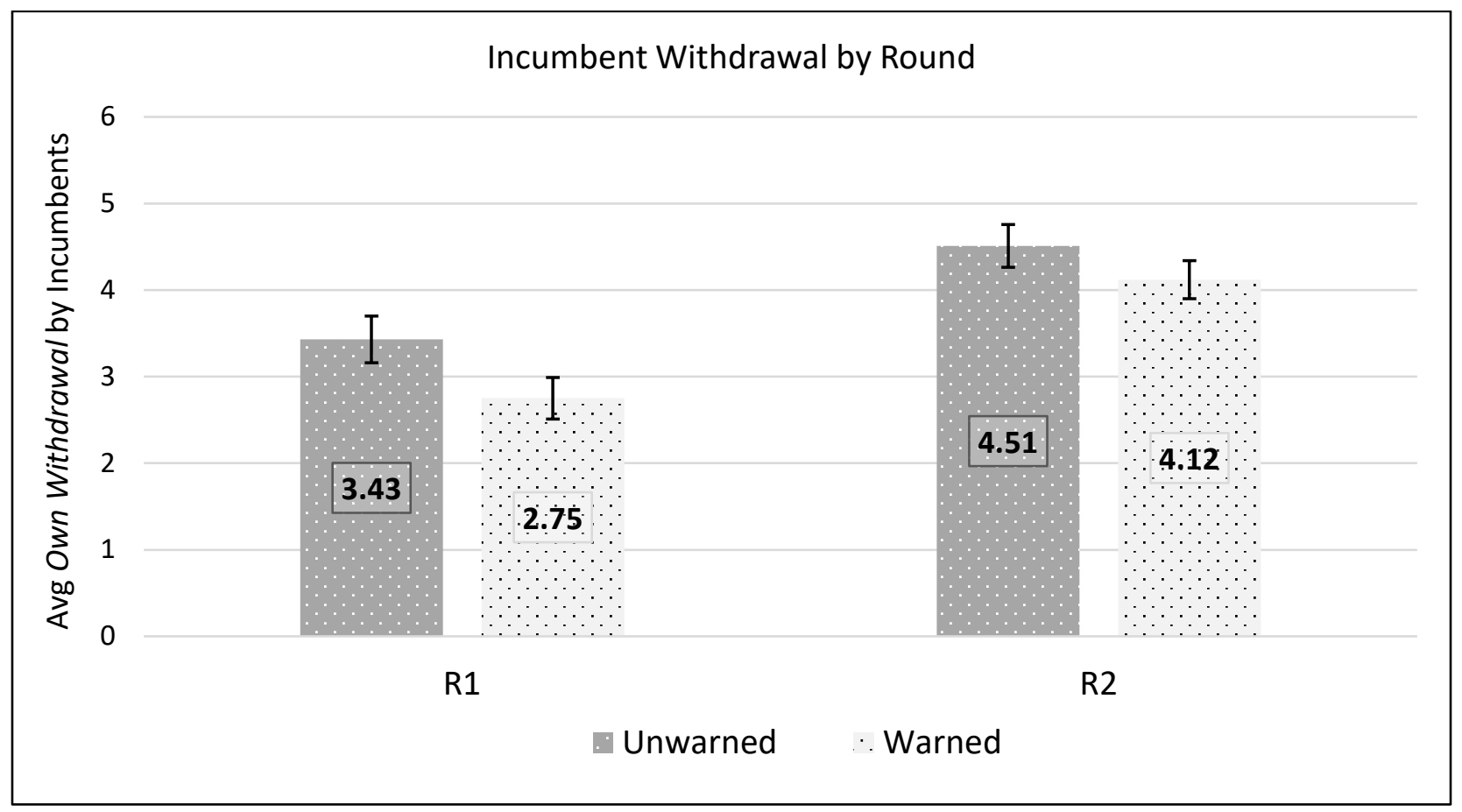

Figure 6. Comparison of average incumbent withdrawals when informed that their reputation for greediness would be shared with a new second round participant (warned) and average incumbent withdrawals when not informed that their reputation for greediness would be shared with a new second round participant (unwarned). Error bars indicate the standard error. There was no significant difference in either R1 or R2 withdrawals by incumbents between the warned and unwarned conditions. 


\section{RUNNING HEAD: IS GREED CONTAGIOUS?}

Figure 7. Average Own Withdrawal, by Greed Perception of Observed Past Behavior (Study 3)

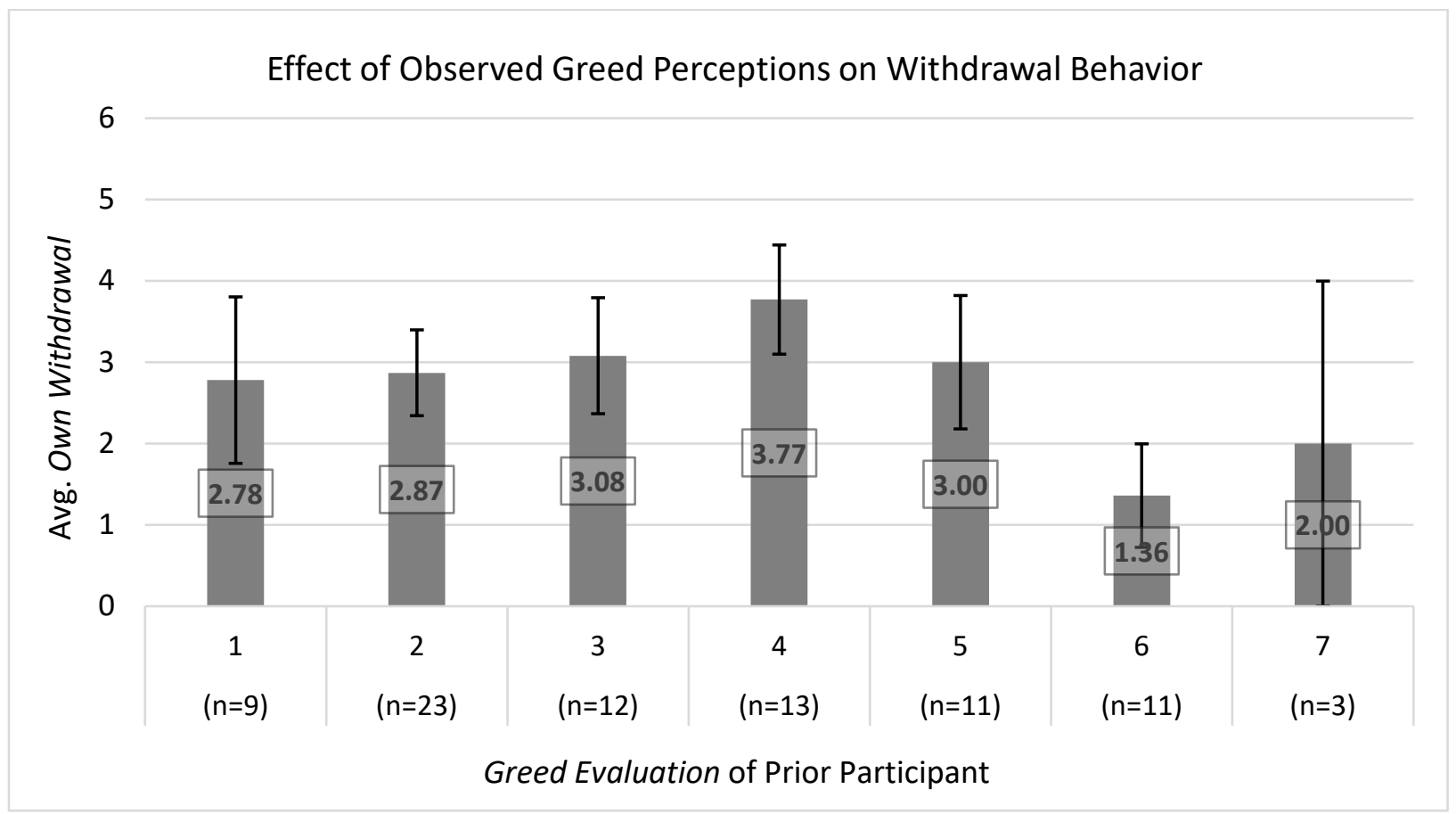

Figure 7. Participants' perception of a prior participant's greed in a previous CPR dilemma and their subsequent withdrawals when playing their own CPR dilemma. The numbers immediately below the $\mathrm{x}$-axis indicate the seven possible integer values of a participant's greed evaluation of the prior participant's withdrawal decision. Because the 3-item greed perception scale does not necessarily result in integer values (each item was on a scale from 1 to 7 ), we rounded greed perceptions to the nearest integer for binning purposes in this figure. Error bars indicate the standard error. The correlation between greed evaluation and own withdrawal is $r=-.12(p=.284)$. 


\section{RUNNING HEAD: IS GREED CONTAGIOUS?}

Figure 8. Consistency of Opponent and Self-Reported Perceptions of R1 Greediness (Study 4)

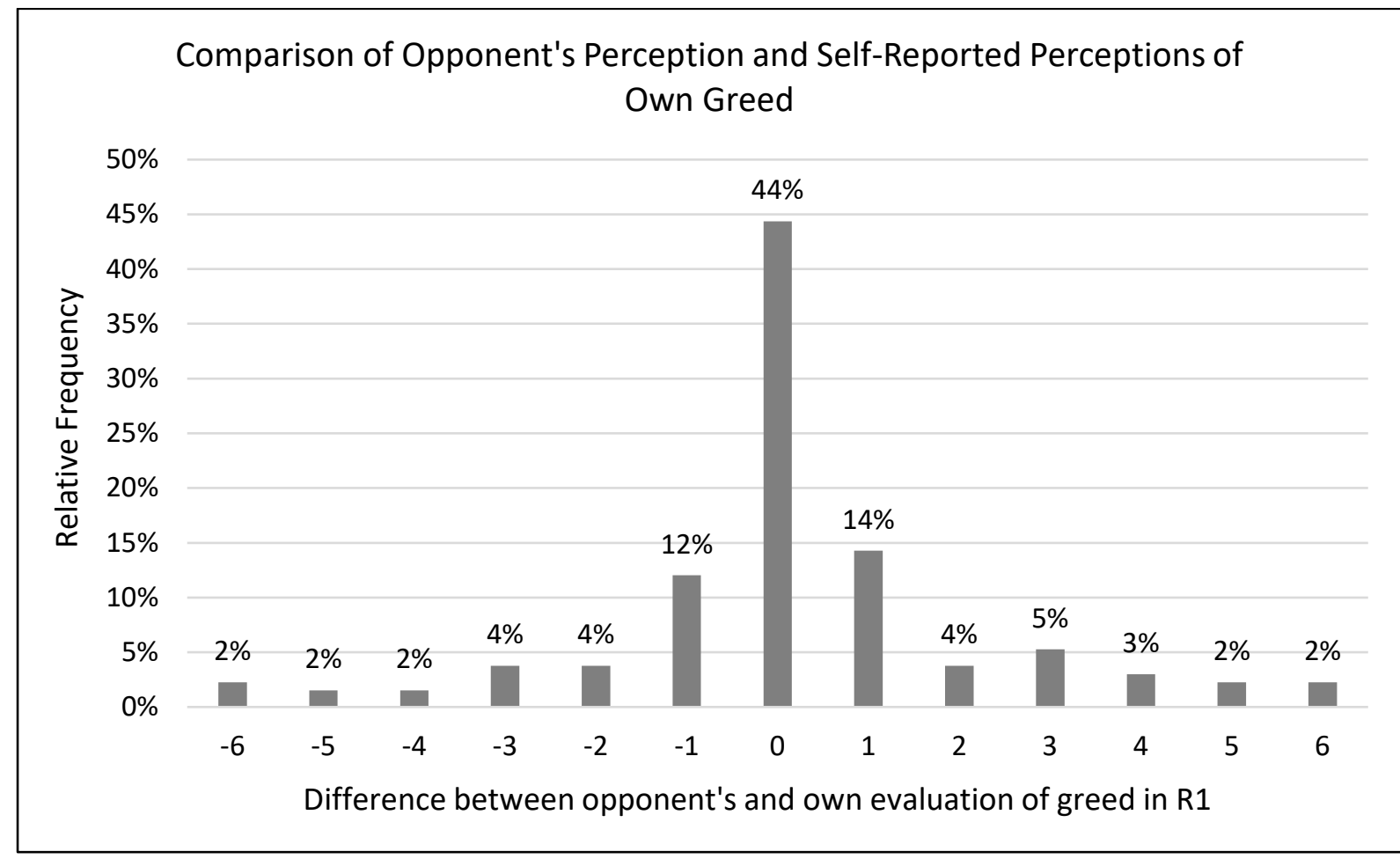

Figure 8. The distribution of differences between the opponent's perception of greed in round 1 and one's own self-reported perception of greed associated with one's own round withdrawal. $71 \%$ of participants' own ratings differed by no more than one scale point from the opponent's rating of their perceived greed in round 1. 


\section{RUNNING HEAD: IS GREED CONTAGIOUS?}

Table 1. Regression Table of the Antecedents of Perceptions of Greed (Study 1)

\begin{tabular}{rccc}
\hline \hline & \multicolumn{3}{c}{ perceived opponent greed R1 } \\
& $(1)$ & $(2)$ & $(3)$ \\
\hline opponent withdrawal R1 & $.645^{* * *}$ & $.640^{* * *}$ & $.809^{* * *}$ \\
& $(.043)$ & $(.044)$ & $(.069)$ \\
own withdrawal $R 1$ & & -.036 & $.135^{*}$ \\
& & $(.043)$ & $(.069)$ \\
opponent withdrawal $R 1$ & & & $-.056^{* * *}$ \\
X own withdrawal $R 1$ & & & $(.018)$ \\
\hline$N$ & 159 & 159 & 159 \\
Adj R-Squared & .583 & .582 & .605 \\
\hline
\end{tabular}

Notes: All coefficients are unstandardized, standard errors reported in parentheses. $R 1$ denotes round one of the two rounds of the CPR dilemma played in Study 1.

$*$, **, and $* * *$ denote significant at the $10 \%, 5 \%$, and $1 \%$ levels, respectively. 


\section{RUNNING HEAD: IS GREED CONTAGIOUS?}

Table 2. Regression Table of the Determinants of Participants' Own R2 Withdrawal (Study 1)

\begin{tabular}{|c|c|c|c|c|}
\hline & \multicolumn{4}{|c|}{ own withdrawal $R 2$} \\
\hline & (1) & $(2)$ & (3) & (4) \\
\hline \multirow{2}{*}{ own withdrawal R1 } & $.761 * * *$ & $.747 * * *$ & $.728 * * *$ & $.760 * * *$ \\
\hline & $(.099)$ & $(.101)$ & $(.102)$ & $(.100)$ \\
\hline \multirow[t]{2}{*}{ opponent withdrawal R1 } & $.814 * * *$ & $.727^{* * *}$ & $.765 * * *$ & $.846 * * *$ \\
\hline & (.099) & $(.136)$ & (.139) & $(.128)$ \\
\hline opponent withdrawal R1 & $-.112 * * *$ & $-.106 * * *$ & $-.105 * * *$ & $-.113 * * *$ \\
\hline Xown withdrawal R1 & $(.025)$ & $(.026)$ & $(.026)$ & $(.026)$ \\
\hline perceived opponent & & .107 & .202 & \\
\hline greed $R 1$ & & $(.115)$ & $(.141)$ & \\
\hline perceived opponent & & & -.217 & -.061 \\
\hline selfishness $R 1$ & & & $(.188)$ & $(.154)$ \\
\hline$N$ & 159 & 159 & 159 & 159 \\
\hline Adj R-Squared & .41 & .41 & .41 & .41 \\
\hline
\end{tabular}

Notes: All coefficients are unstandardized, standard errors reported in parentheses. $R 1$ denotes round one of the two rounds of the CPR dilemma played in Study 1, while $R 2$ denotes round two.

*, **, and $* * *$ denote significant at the $10 \%, 5 \%$, and $1 \%$ levels, respectively. 


\section{RUNNING HEAD: IS GREED CONTAGIOUS?}

Table 3. Regression Table of the Determinants of Incumbents’ Own R2 Withdrawal (Study 2)

\begin{tabular}{|c|c|c|c|c|}
\hline & \multicolumn{4}{|c|}{ own withdrawal $R 2$} \\
\hline & (1) & $(2)$ & (3) & (4) \\
\hline \multirow[t]{2}{*}{ own withdrawal R1 } & $.581 * * *$ & $.589 * * *$ & $.583 * * *$ & $.581 * * *$ \\
\hline & $(.112)$ & $(.113)$ & $(.114)$ & $(.114)$ \\
\hline \multirow[t]{2}{*}{ opponent withdrawal R1 } & $.392 * * *$ & $.317^{* *}$ & $.340 * *$ & $.391 * * *$ \\
\hline & $(.112)$ & $(.141)$ & $(.147)$ & $(.139)$ \\
\hline opponent withdrawal R1 & $-.053^{*}$ & $-.052 *$ & $-.053 * *$ & $-.053 * * *$ \\
\hline X own withdrawal R1 & $(.029)$ & $(.029)$ & $(.029)$ & $(.029)$ \\
\hline perceived opponent & & .114 & .162 & \\
\hline greed $R 1$ & & $(.128)$ & $(.154)$ & \\
\hline perceived opponent & & & -.109 & .003 \\
\hline selfishness $R 1$ & & & $(.193)$ & $(.162)$ \\
\hline$N$ & 148 & 148 & 148 & 148 \\
\hline Adj R-Squared & .25 & .25 & .25 & \\
\hline
\end{tabular}

Notes: All coefficients are unstandardized, and standard errors reported in parentheses. $R 1$ denotes round one of the two rounds of the CPR dilemma played in Study 1, while $R 2$ denotes round two.

$*$, **, and *** denote significant at the $10 \%, 5 \%$, and $1 \%$ levels, respectively. 


\section{RUNNING HEAD: IS GREED CONTAGIOUS?}

Table 4. Regression Table of the Determinants of Participants’ Own R2 Withdrawals (Study 4)

\begin{tabular}{|c|c|c|c|c|c|}
\hline \multicolumn{6}{|c|}{ own withdrawal $R 2$} \\
\hline & (1) & $(2)$ & (3) & (4) & (5) \\
\hline own withdrawal R1 & $\begin{array}{l}.510 * * * \\
(.115)\end{array}$ & $\begin{array}{c}.417^{* * *} \\
(.139)\end{array}$ & $\begin{array}{c}.454 * * * \\
(.141)\end{array}$ & $\begin{array}{c}.461 * * * \\
(.143)\end{array}$ & $\begin{array}{c}.457 * * * \\
(.143)\end{array}$ \\
\hline opponent withdrawal R1 & $\begin{array}{l}.335 * * * \\
(.116)\end{array}$ & $\begin{array}{l}.351^{* * *} \\
(.116)\end{array}$ & $\begin{array}{c}.207 \\
(.152)\end{array}$ & $\begin{array}{c}.194 \\
(.158)\end{array}$ & $\begin{array}{c}.237 \\
(.150)\end{array}$ \\
\hline opponent withdrawal R1 & -.034 & -.032 & -.026 & -.026 & -.028 \\
\hline X own withdrawal R1 & $(.030)$ & $(.030)$ & $(.030)$ & $(.030)$ & $(.030)$ \\
\hline own greed $R 1$ & & $\begin{array}{l}.133 \\
(.112)\end{array}$ & $\begin{array}{l}.115 \\
(.113)\end{array}$ & $\begin{array}{l}.110 \\
(.114)\end{array}$ & $\begin{array}{l}.110 \\
(.114)\end{array}$ \\
\hline $\begin{array}{r}\text { perceived opponent } \\
\text { greed } R 1\end{array}$ & & & $\begin{array}{l}.194 \\
(.134)\end{array}$ & $\begin{array}{c}.155 \\
(.178)\end{array}$ & \\
\hline $\begin{array}{r}\text { perceived opponent } \\
\text { selfishness } R 1\end{array}$ & & & & $\begin{array}{l}.082 \\
(.242)\end{array}$ & $\begin{array}{c}.220 \\
(.182)\end{array}$ \\
\hline$N$ & 133 & 133 & 133 & 133 & 133 \\
\hline Adj. R-Squared & .213 & .216 & .222 & .217 & .218 \\
\hline
\end{tabular}

Notes: All coefficients are unstandardized, and standard errors reported in parentheses. $R 1$ denotes round one of the two rounds of the CPR dilemma played in Study 1, while $R 2$ denotes round two.

$*, * *$, and $* * *$ denote significant at the $10 \%, 5 \%$, and $1 \%$ levels, respectively. 